IZA DP No. 10259

In Front of and Behind the Veil of Ignorance: An Analysis of Motivations for Redistribution

David Bjerk

October 2016 


\title{
In Front of and Behind the Veil of Ignorance: An Analysis of Motivations for Redistribution
}

\author{
David Bjerk \\ Claremont McKenna College \\ and IZA
}

\section{Discussion Paper No. 10259 \\ October 2016}

\author{
IZA \\ P.O. Box 7240 \\ 53072 Bonn \\ Germany \\ Phone: +49-228-3894-0 \\ Fax: +49-228-3894-180 \\ E-mail: iza@iza.org
}

Any opinions expressed here are those of the author(s) and not those of IZA. Research published in this series may include views on policy, but the institute itself takes no institutional policy positions. The IZA research network is committed to the IZA Guiding Principles of Research Integrity.

The Institute for the Study of Labor (IZA) in Bonn is a local and virtual international research center and a place of communication between science, politics and business. IZA is an independent nonprofit organization supported by Deutsche Post Foundation. The center is associated with the University of Bonn and offers a stimulating research environment through its international network, workshops and conferences, data service, project support, research visits and doctoral program. IZA engages in (i) original and internationally competitive research in all fields of labor economics, (ii) development of policy concepts, and (iii) dissemination of research results and concepts to the interested public.

IZA Discussion Papers often represent preliminary work and are circulated to encourage discussion. Citation of such a paper should account for its provisional character. A revised version may be available directly from the author. 


\section{ABSTRACT}

\section{In Front of and Behind the Veil of Ignorance: An Analysis of Motivations for Redistribution*}

This paper uses a laboratory experiment to explore individuals' motivations for redistribution. The laboratory results show that as income uncertainty diminishes, participants become more extreme in their preferences for redistribution. The findings suggest that for most people, the motivation for redistribution is financial self-interest - namely as insurance against future bad luck - rather than furthering equity. However, a non-negligible group of participants propose redistribution levels inconsistent with financial self-interest, where this group is primarily made up of those with the least to lose financially from making such a proposal, and the size of this group increases when participants can communicate prior to proposing. Survey data from the National Longitudinal Survey of Youth and General Social Survey show that these experimental findings may help shed light on the way preferences for redistribution evolve with age in the real world.

JEL Classification: H2, D3

Keywords: redistribution, laboratory experiment, veil of ignorance, progressive taxation

Corresponding author:

David Bjerk

Department of Economics

Claremont McKenna College

500 East Ninth Street

Claremont CA 91711

USA

E-mail: david.bjerk@cmc.edu

\footnotetext{
* Thank you to UCLA'S CASSEL for providing the research facilities to perform this work, as well as the Lowe Institute for Political Economy and the Dean of Faculty's Office at Claremont McKenna College for their generous financial assistance, and seminar participants at UQAM for helpful comments. Thanks to Myles MacDonald for research assistance.
} 


\section{NON-TECHNICAL SUMMARY}

Why do people support income redistribution? Some might say such support comes from individuals' notions of fairness and justice. However, a more self-interested motive may also be at play. Namely, individuals may support redistribution policies because they view them as a way to help insure against future income uncertainty.

Using data from a laboratory experiment, where participants performed tasks that earned them real money, I show that as earnings uncertainty diminishes, those who become certain that they will end up at the top of the earnings distribution become less supportive of redistribution, while those who become certain they will end up at the bottom of the earnings distribution become more supportive of redistribution. I argue that these findings suggest that most individuals' support for redistribution is primarily driven by desires to insure future earnings uncertainty rather than some broader notion of justice.

A question relevant to all social science laboratory experiments is whether the findings extend outside of the lab. To consider this, I examine how stated preferences for redistribution evolve with age. Specifically, I show that in the US population as a whole, earnings uncertainty falls with age. Given this, the results from the lab experiment would suggest that preferences over redistribution should become more extreme as people age, with those at the top of the income distribution becoming less supportive of redistribution with age, while those at the bottom of the income distribution becoming more supportive of redistribution with age. Data from the General Social Survey confirm this to be true.

While the general results of this study suggest that notions of justice play a relatively small role in peoples' motivations for supporting redistribution, the lab results also suggest that this is not immutable. In particular, even modest amounts of communication between the "haves" and the "have nots" can lead the "haves" to becomes substantially more willing to redistribute some of their earnings. 


\section{I - Introduction}

While there are several reasons for taxation, including funding public goods and internalizing externalities, much of the current debate revolves around taxation as a means to redistribute earnings and wealth away from those at the top of the distribution towards those at the bottom. There are a variety of motivations for why a population of citizens may demand such redistribution. For example, individual notions of justice may include achieving some desired amount of equality in financial outcomes in a society. Alternatively, the motivation for redistribution could be more related to financial selfinterest---individuals may see a certain amount of guaranteed redistribution as a form of insurance to protect themselves from possible spells of bad luck in the future.

This paper aims to help shed some further light on the relative strength of these different motivations for redistribution. In particular, this study considers a laboratory experiment in which participants earn money by successfully completing a series of tasks, where the payoff to a successful task is randomly and differentially determined across participants. I then consider two primary treatments regarding how participants propose different levels of redistribution of earnings. In the first primary treatment, participants first complete tasks and learn their earnings and the earnings of others, after which they are asked to propose a redistribution level. This treatment is referred to as the Earnings Known treatment. In the second primary treatment, participants must propose a redistribution level "behind-the-veil of ignorance," or in other words, they must propose a level of redistribution before performing any tasks, knowing anything about what their earnings will end up being, or where their earnings will lie in the subsequent distribution of earnings. This is referred to as the Earnings Unknown treatment. Under both treatments, all those with earnings above the mean will have some of their earnings taxed away, while all those with earnings below the mean will receive an earnings subsidy, where the tax and subsidy rates are higher under a higher level of implemented redistribution. The implemented redistribution level is determined at random from the distribution of redistribution levels proposed by the participants.

Under the Earnings Unknown treatment, where participants make their redistribution proposals before they know anything about their earnings outcome, those who propose any strictly positive level of redistribution can be motivated either by 
financial self-interest, namely they propose positive levels of redistribution to act as a form of insurance, or be motivated by some sense of what they feel is a just or more equitable distribution of final earnings. However, under the Earnings Known treatment, complete financial self-interest would lead participants to propose either no redistribution (for those with earnings above the mean) or complete redistribution (for those with earnings below the mean), where complete redistribution means splitting aggregate earnings equally across all participants. Proposing a level of redistribution that is not one of these two extremes can only be motivated by some demand for a more "fair" or "just" distribution of final payouts. Therefore, comparing the distribution of proposed redistribution levels under the Earnings Known treatment to the Earnings Unknown treatment should give some indication about how much of the demand for redistribution in the Earnings Unknown treatment is due to financial self-interest---i.e., insuring against earnings uncertainty---and how much is due to preferences regarding justice and fairness of outcomes.

Under the Earnings Unknown treatment, over eighty-five percent of participants propose a strictly positive amount of redistribution, with most proposing a relatively modest amount of redistribution and less than ten percent proposing complete redistribution. As stated above, any strictly positive proposed redistribution under this treatment could either be motivated by financial self-interest or by some other sense of justice. By contrast, in the Earnings Known treatment, the distribution of proposed levels of redistribution was bimodal, with roughly seventy percent of participants proposing either complete redistribution or no redistribution whatsoever, with the majority of those who ended up in the upper half of the earnings distribution proposing no redistribution and the majority of those who ended up in the lower half of the distribution proposing complete redistribution.

Given the two treatments differed only in the timing of when participants were asked to propose a level of redistribution, and the vast majority of participants acted with complete financial self-interest under the Earnings Known treatment, these results suggest that for most individuals, the demand for redistribution under the Earnings Unknown treatment was actually motivated by monetary self-interest---namely as a form of insurance against future earnings uncertainty---rather than some desire for a particular 
distribution of payoff outcomes for the group. However, a small but non-negligible fraction of participants seem to have other motivations besides self-insurance, as roughly thirty percent of participants chose an interior level of redistribution in the Earnings Known treatment, a choice that cannot have been motivated by pure financial selfinterest. This group was primarily made up of those in the middle of the earnings distribution, or in other words, those for whom it was "cheapest" to not act with complete financial self-interest.

Interestingly, under a new treatment that was identical in all ways to base Earnings Known treatment discussed above except that earnings were determined completely at random rather than via correctly answered questions (hereafter referred to as the Earnings Known- Random treatment), behavior with respect to redistribution was essentially identical to the base Earnings Known treatment. However, under a second subsequent treatment, that again was identical to the base Earnings Known treatment except that participants were allowed to anonymously communicate with each other prior to proposing their preferred amount of redistribution (hereafter referred to as the Earnings Known- Communication treatment), a substantially higher fraction of individuals who ended up in the upper half of the earnings distribution now chose to propose a relatively high level of redistribution rather than zero. This suggests even small amounts of dialog across individuals in different situations can potentially have large impacts on individual's preferences over redistribution.

The final part of the paper attempts to explore some of the implications of the lab experiment using real world survey data. In particular, if preferences for redistribution are primarily driven by a desire to insure against future financial uncertainty for most people, as suggested in the lab experiment discussed above, then as people become more and more certain about their overall financial position, their preferences for redistribution should move toward the extremes of either preferring a lot of redistribution or preferring very little redistribution. Using data from the National Longitudinal Survey of Youth 1979 and the General Social Survey, I show that this implication can potentially help us understand why preferences for redistribution evolve with age.

\section{II - Related Literature}


Much of the motivation for the experimental environment examined here arises from John Harsanyi (1955), and Rawls (1971, 2001). In paricular, Rawls’ considers the question "(w)hat would a just democratic society be like under reasonably favorable but still possible historical conditions, conditions allowed by the laws and tendencies of the social world?" (Rawls, 2001: p 4). To consider this question, he attempts to consider what type of principles free and rational individuals would agree upon in a situation where "no one knows his place in society, his class position or social status, nor does anyone know his fortune in the distribution of natural assets and abilities, his intelligence, strength, and the like," a situation he describes as behind the veil-of-ignorance (Rawls, 1971: p 12)

While Rawls' conclusions from this thought exercise have been critiqued (see for example Harsanyi 1975), the thought exercise illuminates a interesting question---to what extent are people's notions of distributive justice influenced by their realized outcomes in society? And relatedly, to what extent are people's notions of what constitutes a just organization of society motivated by their uncertainty regarding what their future holds?

Rawls' argues that from this behind-the-veil of ignorance construct, individuals would agree upon policies that would maximize the well-being of the worst off members of society. While he denoted this outcome as "justice," much of the motivation he gives for why individuals behind-the-veil of ignorance would choose such a criteria is individual risk-aversion to ending up at the bottom of society. Therefore, while Rawls' contends that maximizing the well-being of those worst off in society is what constitutes a just society, this is in some sense based on an argument that free and equal people would agree to this behind-the-veil of ignorance because of a self-interested desire to insure themselves against a very bad outcome.

This behind-the-veil thought exercise has motivated several different experiments in the lab. Most directly, Frohlich, Oppenheimer, and Eavey (1987a), Frolich, Oppenheimer, and Eavey (1987b), and Frolich and Oppenheimer (1990) explicitly try to replicate Rawls' proposed environment and test his conclusions in a laboratory setting. The main findings of these works show that indeed subjects could generally reach consensus, but subjects do not arrive at the option most closely replicating Rawls' 
prediction. Namely, rather than maximizing the lowest income, subjects overwhelmingly choose to maximize average income with a floor constraint.

As discussed in the introduction, the experiment developed here also has a type of "behind-the-veil of ignorance" treatment. However, the interest of this paper is to directly compare how the preferences for redistribution differ between such a behind-the-veil treatment (the Earnings Unknown treatment) and a treatment where individuals choose their preferred level of redistribution after they know where their earnings lie in the overall distribution of earnings (the Earnings Known treatment).

In some ways, the Earnings Known treatment has similarities to a large swath of the experimental literature on altruism and public goods, most notably Dictator games (see Camerer 2003 for summary of much of this work). However, one could argue that most such Dictator experiments are not necessarily looking at individual's tastes for redistribution in a society, but rather are looking at tastes for altruism or charity within a particular context. In general, the literature on games where subjects must decide how much of their realized wealth to share with others reveals that behavior is very much affected by the way the game is set up. ${ }^{1}$

Schildberg-Horisch (2010) uses laboratory Dictator type games but implements them in an "In Front of/Behind the Veil" type manner somewhat analogous to that used here. In particular, she compares behavior in a standard dictator type experiment to two slightly altered dictator games. In the first, participants must choose how much the dictator will give away before knowing whether they will fill the role of the dictator or the receiver in the game. In the second, participants must choose how much the dictator will give away before knowing whether they will fill the role of the dictator or the receiver in the game, and knowing that whatever role they do not fill will be empty (i.e., it is just a one-person game). Comparing outcomes in these slightly altered dictator

${ }^{1}$ For example, behavior is drastically different when the dictator's decision is framed as taking rather than giving (List 2007), when dictators are also given the option of taking some of their partner's allotment rather than just sharing some of their own allotment with their partner (Bardsley 2008), whether the allotments to be shared are "produced" or "earned" rather than just randomly allocated (Cappelen et al. 2007; Krawczyk 2010), how many people will benefit from the redistribution decision (Andreoni 2007), when subjects are placed in identifiable groups together (Klor and Shayo 2010), when the recipient is generally agreed to be "more deserving" (Eckel and Grossman 1996), how much of the "endowment" is initially allocated to the dictator versus the "receiver" (Hayashi 2013), and when the dictator is guaranteed greater anonymity (Hoffman, McCabe, and Smith 1996). 
games relative to the standard dictator setup can reveal the relative influence of individual monetary risk versus social altruism in sharing behavior.

Rutstrom and Williams (2000) look explicitly at preferences for redistribution in a laboratory framework from a context where each individual knows where he or she lies in the income distribution when he or she proposes a level of redistribution. They find that most subjects propose the level of redistribution that maximizes their own personal payoff, and these proposals do not seem to be affected by how each subjects' initial entitlement is allocated.

One experimental environment that quite closely resembles the one used in this paper is that used by Esarey, Salmon, and Barrilleaux (2012a). Their experimental set-up proceeds in three distinct stages. First, participants "produce" income (by answering spelling questions) without any redistributive tax for three periods. Second, participants propose a redistributive tax and then "produce" income (by again answering spelling questions) under this redistributive tax for three periods. Finally, participants propose a new redistributive tax and then again "produce" income in the same manner as before under this new redistributive tax for three periods.

The key difference between the design used here and that used by Esarey, Salmon, and Barrilleaux's (2012a) is that in their setup, not only is income earned in the same manner each period (via a spelling test), but also each participant has several rounds of information about his or her ability with respect to this income generating mechanism relative to the other participants before making any redistribution proposals. Therefore, in Esarey, Salmon, and Barrilleaux's (2012a) design, at the time a participant makes a redistribution proposal, she has considerable though not perfect information upon which to base her expectations of where she will lie in income distribution at the time of redistribution. By contrast, the design used here is much starker. As will be discussed in more detail below, subjects make their redistribution decisions either with full information regarding their own earnings and where they lie in the earnings distribution, or with essentially no information upon which to even base their expectations of where they will eventually lie in the earnings distribution at the time of redistribution.

Durante et al. (2014) also use an experimental framework similar to that used here. Their design is also a three-stage process for each player, where each player first 
must choose a redistribution rules that will not affect himself, then must choose a redistribution rule that will affect himself but done so before he knows where he will lie in the earnings distribution, and finally must choose a redistribution rule that will affect himself but after he knows where he lies in the earnings distribution. One of the important contributions of this three-stage design is that it allows the authors estimate utility weights regarding several different motivations for redistribution. However, in order to do so, they have each participant make redistribution decisions first "behind" then "in front of" the veil of ignorance. One question is whether the redistribution decisions made behind the veil of ignorance influence the subsequent redistribution decision made after earnings uncertainty is eradicated. In the experimental design below, each subject makes the redistribution decision either "in front of" or "behind" the veil of ignorance, not both, so the participants making a redistribution decision after all earnings uncertainty has been resolved have not been "primed" by thinking about redistribution in a more general sense. The experimental design below also differs from Durante et al. (2014) (as well as Esarey, Salmon, and Barrilleaux (2012a)) in that it also includes a "communication" treatment, where participants make a redistribution decision after they know where they lie in the earnings distribution, but after they engage in anonymous non-binding communication with all the other participants.

A final contribution of this paper relative to Esarey, Salmon, and Barrilleaux (2012a) and Durante et al. (2014) is that it looks to supplement the laboratory results with non-laboratory survey results regarding preferences for redistribution. Several other papers consider preferences for redistribution outside of the lab. For example, Corneo and Fong (2008) use the 1998 Gallup Poll Social Audit Survey to show that Americans' willingness to pay for a more distributively just society is substantial, and Fong (2001) uses the same data to find evidence suggesting that self-reported preferences for redistribution are at least somewhat predicted by an individual's beliefs about the role of effort versus luck in determining outcomes. Similar results were found by Alesina and La Ferrara (2005) using different survey data. Ravallion and Lokshin (2000) and Corneo and Gruner (2002) find evidence that individuals' stated demand for redistribution is related to their self-assessed likelihood of being upwardly mobile in Russia and several OECD 
countries respectively. Finally, Kerr (2014) finds evidence that suggests higher inequality tends to lead to stronger support for government redistribution.

While these studies are certainly helpful for understanding what determines the demand for redistribution, one inherent constraint in such study designs is that preferences for redistribution are taken from self-reported hypotheticals, rather than obtained via revealed preference. One advantage of the laboratory environment is that preferences for redistribution can be measured through revealed behavior. However, this comes at the cost of questionable external validity (Levitt and List 2007). Therefore, the study below not only studies revealed preferences regarding redistribution directly through choices made in a controlled lab environment, but also attempts to examine some of the implications of this lab behavior outside of the lab setting.

\section{III - Experiment}

\section{III(a) - Basic Design}

The experiment developed here has two primary treatments that differ only in the timing of when certain decisions must be made. In each round of each treatment, a group of $n$ participants is asked to complete a series of "tasks" (in the context of the actual experiment, these "tasks" consist of answering different types of questions such as GRE mathematics questions, sport trivia, vocabulary, etc). For each successfully completed task (i.e., correct answer) a participant $i$ earns $r_{i}$ tokens, where $r_{i}$ is a randomly drawn variable each round that differs across participants but is known to the participant at the time he or she performs his or her tasks (but not to the other participants). An individual's "Earnings" in a given round, $\pi_{\mathrm{i}}$, will then equal to $\mathrm{s}_{\mathrm{i}} \mathrm{r}_{\mathrm{i}}$, where $\mathrm{s}_{\mathrm{i}}$ is individual $i$ 's number of successfully completed tasks and $r_{i}$ is individual $i$ 's return to each successfully completed task.

Each player must also propose a "redistribution rule" denoted by $p$, which is a number between zero and one (in increments of 0.01 ), where $p$ represents what fraction of each participant's task earnings will be taken from each participant and split equally across all participants. The actual redistribution rule $p$ that is implemented in any given 
round is chosen by the experiment administrator at random from all of the participants' proposed redistribution rules in a given round. ${ }^{2}$

Given a particular implemented redistribution rule $p$, a player i's net payoff from a given round is then given by

$$
\mathrm{V}\left(\pi_{\mathrm{i}}, p\right)=(1-p) \pi_{\mathrm{i}}+\Sigma_{\mathrm{j}=1}^{\mathrm{n}}\left(p \pi_{\mathrm{j}}\right) / \mathrm{n}
$$

or equivalently

$$
\mathrm{V}\left(\pi_{\mathrm{i}}, p\right)=(1-p) \pi_{\mathrm{i}}+p \pi_{\text {mean }}
$$

So, for example, suppose player $i$ has task earnings of 12 tokens in a given round and the mean task earnings of all participants in that round is 8 tokens. Then, if player $i$ chose a $p$ $=0.25$ and he was chosen to be the random dictator in this round, his net payoff in this round would equal $(1-0.25) * 12+0.25 * 8=11$ tokens. Alternatively, if someone else who chose a $p=0.50$ was chosen to be the random dictator, then player $i$ 's net payoff in this round would be $(1-0.5) * 12+0.5 * 8=10$ tokens.

Clearly, as can be seen in equation (1), for those whose earnings lie above the mean (i.e., $\pi_{\mathrm{i}}>\pi_{\text {mean }}$ ), net monetary payoff will be maximized if $p=0$. Alternatively, for those whose earnings lie below the mean (i.e., $\pi_{\mathrm{i}}<\pi_{\text {mean }}$ ), net monetary payoff will be maximized if $p=1$.

The redistribution mechanism used here is essentially equivalent to a progressive income tax/subsidy. Specifically, note that the "tax" associated with any given earnings and $p$ can be denoted $\mathrm{t}\left(\pi_{\mathrm{i}}, p\right)=\pi_{\mathrm{i}}-\left[(1-p) \pi_{\mathrm{i}}+p \pi_{\text {mean }}\right]$, or by simplifying,

$$
\mathrm{t}\left(\pi_{\mathrm{i}}, p\right)=p\left(\pi_{\mathrm{i}}-\pi_{\text {mean }}\right)
$$

To determine the implicit tax rate, we can divide this expression by task earnings $\pi_{\mathrm{i}}$ and simplify, giving us

\footnotetext{
2 This is sometimes known as a "random dictator" mechanism and is meant to ensure that it is in each player's best interest to truthfully reveal his or her preferred redistribution rule.
} 


$$
\tau\left(\pi_{\mathrm{i}}, p\right)=p\left(1-\pi_{\text {mean }} / \pi_{\mathrm{i}}\right)
$$

Note, this tax and tax rate will be positive (meaning an individual's net "after-tax" payoff will be lower than his/her task earnings) if $\pi_{\mathrm{i}}-\pi_{\text {mean }}>0$, but will be negative (meaning an individual's net "after-tax" payoff will be higher than his/her task earnings) if $\pi_{\mathrm{i}}-\pi_{\text {mean }}<$ 0 . Moreover, for those with a positive tax rate, it is straightforward to see from both equations (2) and (3) that the size of both the tax and the tax rate are increasing in an individual's task earnings $\pi_{\mathrm{i}}$. Similarly, for those with a negative tax rate, meaning they receive a tax subsidy, the size of this subsidy and the size of this subsidy relative to their earnings is decreasing in an individual's task earnings $\pi_{\mathrm{i}}$.

\section{III(b) - Primary Treatments}

As stated in the introduction above, there are two primary treatments that differ only with respect to timing of decisions and information. In the Earnings Known treatment, participants first learn their rate-of-return on task successes $r_{i}$ for that round, then learn the nature of the tasks for that round (i.e., what types of questions will be asked), then attempt to perform these tasks answer (i.e., answer questions), then observe how many task successes $\mathrm{s}_{\mathrm{i}}$ they achieve, and finally are told their resultant earnings for that round, as well as the mean earnings and where their earnings lie in the distribution of all participants earnings for that round. ${ }^{3}$ After learning all of this, each participant is asked to propose a re-distribution rule $p$ which can vary from zero to one in increments of 0.01 (though, it should be clear that at the beginning of the round, participants know they will be asked to propose a redistribution rule after at the end of the round after they learn their rate-of-return, number of correct answers, and resultant earnings for that round).

The other primary treatment is the Earnings Unknown treatment in which participants must each propose their desired re-distribution rule $p$ before they learn either their rate-of-return on task successes $r_{i}$, the nature of the tasks, or how many task successes $\mathrm{s}_{\mathrm{i}}$ they achieve. In other words, the Earnings Unknown treatment is arguably a

\footnotetext{
${ }^{3}$ Specifically, they observe a list of everyone's earnings that round from smallest to largest with their own earnings highlighted, as well as the mean earnings that round.
} 
Behind-the-Veil type environment in that participants had very little information on which to base their expectations regarding where they would end up in the earnings distribution for each round.

\section{III(c) - Game Procedures}

Participants were recruited from the undergraduate student population at UCLA via classroom visits and flyers posted around campus. Forty-nine percent were female. When asked "How would you describe your political leanings," two percent answered "extremely conservative," four percent answered "conservative," seventeen percent answered "moderately conservative," twenty-two percent answered "moderately liberal," thirty-one percent answered "liberal", twelve percent answered "very liberal," and the remaining eleven percent answered "none of the above." This distribution suggests this experimental group may be somewhat more liberal than the U.S. population at large, which is not surprising given the age group and social context the subjects live in. ${ }^{4}$

Two sessions of each of the two primary treatments were conducted, with a total of 86 distinct participants spread across these four sessions. Each participant participated in only one session and therefore in only one treatment. All participants in the same session participated at the same time in one room via an individual computer in an individual cubicle, and formed one "experimental" group. A treatment session consisted of one practice round and six "real" rounds. In each session, prior to the practice round, participants were carefully instructed on the rules of the game via a script (for their treatment only), as well as how final payoffs are determined in each round and for the experiment as a whole. ${ }^{5}$

As alluded to above, "tasks" consisted of answering questions. However, the type of questions that participants were asked in the "task" completion stage differed by round and only one type of question was asked in any given round. Types of questions included GRE math questions, general trivia questions, sports trivia questions, movie and celebrity trivia questions, GRE type analogy questions, and GRE type sentence completion questions. Participants knew that the type of questions would differ every round, but as

\footnotetext{
${ }^{4}$ In a 2009 Gallup Poll of the US population, 9\% described themselves as "very conservative, " 31\% "Conservative," 35\% "Moderate," 16\% "Liberal," 5\% "Very Liberal," and 4\% "No Opinion."

${ }^{5}$ The instruction script that was read to the participants in the Earnings Unknown treatment are included in the Appendix. Instructions that were read to participants in the other treatments are very similar and available from the author upon request.
} 
stated above, did not know the exact type of the questions until they commenced a given round (see Appendix for examples of questions participants were asked in different rounds). Each round, participants answered as many questions as they could in four minutes.

As stated above, the Earnings Unknown treatment is an attempt to create a behind-the-veil of ignorance type environment, where individuals should all have similar expectation with respect to where they will end up in the eventual earnings distribution. The fact that participants knew the types of questions would differ each round, but didn't know exactly how, is an attempt to facilitate this. To the extent participants felt confident that they would do relatively well (or relatively poorly) in answering any type of question would mitigate this a little bit. However, recall that participants also did not know their rate-of-return on correctly answered questions at the beginning of each period in the Earnings Unknown treatment, meaning even if participants felt they would do relatively well (or relatively poorly) in answering any type of question, there still would be considerable uncertainty regarding where they would end up in the earning distribution at the beginning of each round. As shown below, there is evidence that participants in the Earnings Unknown treatment did not notably differ from each other in their expectations regarding their eventual place in the earnings distribution at the end of each round.

Participants answered questions and made redistribution proposals via a computer. Participants submitted redistribution proposals each round via an electronic slider that moved from zero to one in increments of 0.01. Earnings and payoffs were stated in terms of "tokens," but participants were told at the beginning of the experiment that each token was worth $\$ 0.10$. $^{6}$

As stated above, in the Earnings Known treatment, participants not only knew their own earnings (in tokens) prior to choosing a redistribution level, but also viewed a screen showing the mean earnings over all participants that round, as well as a listing of the earnings of all participants' that round ordered from smallest to largest with their own earnings highlighted. Participants in the Earnings Unknown treatment were also shown

\footnotetext{
${ }^{6}$ See Appendix for screen shots showing the re-distribution proposal screen (for the Earnings Known treatment) and the end of round results screen.
} 
this information, but not until the end of a round after they had made their redistribution decision.

As alluded to in the introduction, the actual redistribution level $p$ that was implemented at the end of each round was chosen at random from all of the participant proposals that round (i.e., a "random dictator"). Redistribution was implemented this way as participants have no incentive not to propose their most preferred redistribution level under this mechanism, and it is quite simple to explain to participants. At the end of each round, participants were informed again of their own earnings from that round, the level of redistribution they proposed, the level of redistribution that was implemented, and their final payoff for that round after redistribution.

Figure 1 summarizes the procedures of the two primary treatments. As can be seen, the only difference between them is when participants choose a redistribution rule (step 2 in Earnings Unknown versus step 5 in Earnings Known).

Final experiment payouts were determined by using the net payoffs for each participant from one of the six "real" rounds chosen at random. The mean final earnings participants walked away with was just over $\$ 10$ plus a $\$ 5$ show up fee. Median earnings were just under $\$ 10$, with the top one percent earning in excess of $\$ 20$ and the lowest $1 \%$ earning just under $\$ 4$. All these earnings were in addition to a $\$ 5$ participation payment. Sessions generally lasted around 45 minutes.

\section{IV - Results}

\section{IV(a) - Basic Analysis}

Figure 2 shows the key results coming from the two primary treatments. Looking first at the results for the Earnings Unknown treatment we can see that while participants proposed redistribution rules ranging from zero to one, the bulk of the distribution lies below $p=0.5$ with a mean of 0.4 and a median of 0.35 . However, it is also notable that less than 15 percent of participants proposed no redistribution whatsoever (i.e., $p=0$ ). As discussed above, the motivations for positive proposed re-distribution rules in this Earnings Unknown treatment could be either as personal insurance against a subsequent low-earning outcome, or due to preferences over what constitutes a "just" distribution of payoffs, or some combination of the two. 
The results under the Earnings Known treatment in Figure 2 look quite different. Specifically, as Figure 2 shows, the vast majority of participants in the Earnings Known treatment (almost 70 percent) chose a re-distribution rule $p$ equal to zero or one, leading to a mean and median of 0.5 for the proposed redistribution rules. Standard errors (adjusted for multiple observations per person) are shown in parentheses above each bar. A joint F-test can reject the hypothesis that this distribution is equal to the distribution of proposed redistribution rules under the Earnings Unknown treatment ( $\mathrm{p}$-value $<0.0001$ ). ${ }^{7}$

Figure 3a shows that in the Earnings Known treatment, the vast majority of those whose earnings were above the mean earnings in a given round proposed a redistribution rule for that round that entailed no redistribution $(p=0)$, while those who earned below the mean level of earnings in a given round proposed complete redistribution of earnings $(p=1)$, or perfect payoff equality, for that round. As can be seen, over 70 percent of those with earnings above the mean proposed no redistribution. Alternatively, only 6 percent of those with earnings above the mean proposed complete redistribution, while almost 60 percent of those with earnings below the mean proposing complete redistribution.

Figure $3 \mathrm{~b}$ shows the analogous results for the Earnings Unknown treatment. This graph shows that the distribution of proposed redistribution rules is quite similar for those who ended up earning above the mean in their round compared to those who ended up earning below the mean in their round. Indeed, a joint F-test (that adjusts for multiple observations per subject) cannot reject the hypothesis that these two distributions are equal ( $\mathrm{p}$-value of 0.50 ). Hence, it does appear that individuals were effectively behind the veil-of-ignorance when they made their redistribution decisions in the Earnings Unknown treatment.

Comparing the results under the Earnings Unknown treatment to the results from the Earnings Known treatment suggest that, at least under this setup, most of the demand for redistribution under the Earnings Unknown treatment was due to individuals attempting to insure themselves against a low earning outcome, not underlying

\footnotetext{
${ }^{7}$ The F-test jointly tested the null hypothesis of equality for each of the deciles in the two distributions. Standard errors, and therefore statistical significance levels, were adjusted for the fact that each individual provided multiple data points by clustering at the individual level. Such a clustering adjustment was done for all the statistical tests that follow in this paper.
} 
preferences for a certain amount of redistribution on some sort of justice grounds. However, it is also notable that a non-negligible fraction of participants in the Earnings Known treatment chose a redistribution rule that did not maximize their financial selfinterest. I will analyze this group more closely later in the paper.

One concern regarding these results might be that how participants fared in early rounds, or what redistribution rules were implemented in earlier rounds, affected participants' behavior in the later rounds. However, this does not appear to be the case as for both the Earnings Unknown and the Earnings Known Treatments, a joint F-test cannot reject the hypothesis that the distribution of proposed redistribution rules is the same in the first three rounds as it is in the latter three rounds at any standard level of significance for either treatment ( $p$-values of 0.19 and 0.70 for each treatment respectively).

Finally, Table 1 shows that the neither the timing of the redistribution decision nor the round appear to have had any substantial impact on the effort put forth in answering questions. The first two columns of numbers in the top panel show that the distribution of earnings across individuals by round was quite similar across treatments and the second two columns of numbers show the actual distribution of correct answers across individuals by round for each treatment. ${ }^{8}$ Note that these columns are almost identical across treatments. Moreover, comparing the results in the two bottom panels of Table 1 show that earnings per person by round, and number of correct answers per person by round, appear to be almost identical in the first three rounds to the latter three rounds under both treatments.

\section{IV(b) - Additional Treatments}

I also conducted two additional treatments that supplement the base Earnings Known treatment discussed above. The first considers whether the bimodal financial payoff maximizing behavior exhibited in the base Earnings Known treatment was simply a byproduct of the fact that earnings are partially due to the participants" "skill" in answering questions. Namely, while earnings were due to both a randomly determined rate-of-return and correct answers to questions in the base Earnings Known treatment,

\footnotetext{
${ }^{8}$ Earnings are shown in tokens, which was how they were revealed to participants during the course of the experiment. However, participants were explicitly told at the outset of each session the that each token would be worth $\$ 0.10$.
} 
individuals who obtained high earnings may have felt that their "skill" made it fair for them to keep their entire earnings, while those who obtained low earnings may have focused on the random nature of how earnings were allocated and thereby consider a greater amount of redistribution to be a more favored outcome due to equity principles. As discussed in Section II, whether earnings/endowments are determined randomly or through some aspect of "skill," or even just the distribution of initial earnings/endowments, has been shown to affect individuals' willingness to redistribute wealth under some experimental setups (Krawczyk 2010; Hayashi 2013; Esarey, Salmon, and Barrilleaux 2012b; Cappelen et al. 2007).

To consider this issue, I ran a further treatment identical in all dimensions to the base Earnings Known treatment described above, but instead of earnings being determined via both the randomly determined rate-of-return on correct answers and the number of correct answers, earnings were entirely determined at random (Earnings Known - Random treatment). Participants simply learned their randomly determined earnings for a given round, and observed the mean and overall distribution of the randomly determined earnings for all participants in that round, and then proposed a redistribution rule. The question and answer portion of the experiment was completely omitted (looking back to Figure 1, procedures were the same as the Earnings Known treatment but steps 2 and 3 were omitted). Participants were also explicitly told that each player's earnings each round were completely randomly determined. A total of 35 new participants over two sessions participated in this treatment, again each playing six rounds.

Figure 4 shows the results of this Earnings Known- Random treatment compared to the base Earnings Known treatment discussed previously. As can be seen, the bimodal nature of the proposed redistribution rules holds across both treatments. More generally, a joint F-test cannot reject the hypothesis that the distributions of proposed distribution rules under the two treatments are the same (p-value of 0.49). Hence, how earnings were determined did appear to affect behavior regarding desired redistribution levels in this environment. While this is somewhat in contrast to some of the studies cited above, it is similar to the results from Durante et al. (2014) in an experimental setup quite similar to this one (see Figure 3 in their paper). 
The second variation to the Earnings Known treatment that I conducted was again similar in all respects to the base Earnings Known treatment discussed in the previous section except that participants were allowed to communicate anonymously with each other after learning their earnings for a given round and observing where their earnings lied in the overall distribution of earnings, but before proposing a redistribution rule for that round (looking back to Figure 1, procedures were the same as the Earnings Known treatment but an additional communication step was included after step 4). This is referred to as the Earnings Known - Communication treatment. Subjects were allowed to communicate in writing for 5 minutes in a virtual chat room integrated into the experimental software. As shown by Yamamori et al. (2008) in the context of dictator games and Charness and Dufwenberg (2006) more broadly, simply allowing some form of communication can alter the willingness of individuals to share. A total of 40 new participants over two sessions participated in this treatment, again each playing six rounds.

Figure 5 shows the results coming from this Earnings Known - Communication treatment, again in comparison to the base Earnings Known treatment discussed above. Interestingly, it appears that for a relatively large fraction of individuals, the anonymous communication that took place prior to proposing redistribution rules impacted their behavior. When communication is allowed, a smaller fraction of individuals end up proposing no redistribution $(p=0)$, with a correspondingly higher fraction of individuals proposing a $p=0.5$, which corresponds to a relatively large amount of redistribution. Indeed, a joint F-test can reject the equality between these two distributions at the one percent level (p-value 0.005). Notably, the fraction of participants proposing no redistribution $(p=0)$ falls from almost 35 percent in the base Earnings Known Treatment to only about 15 percent in the Earnings Known - Communication treatment, and the fraction of participants proposing a $p=0.5$ grows from about 5 percent in the base Earnings Known treatment to over 25 percent in the Earnings Known - Communication treatment.

These results suggest that even a very modest amount of anonymous communication can have a significant impact on many individuals' willingness to redistribute some of their wealth to the less fortunate. Regretfully, the messages posted in 
the virtual chat room were not saved. Hence, what was said is not known and therefore cannot be analyzed directly. Note however, that while the fraction of individuals proposing no redistribution $(p=0)$ is over fifty percent lower in the communication treatment, the fraction proposing complete redistribution $(p=1)$ remained at just over 30 percent in both treatments, suggesting communication did not cause individuals with low earnings to become more likely to opt for less redistribution. One could potentially interpret these results in the context of Konow's (2000) conception that in some interactions individuals face an internal conflict between maximizing their material utility and acting in a way consistent with their notions of fairness, and therefore sometimes reduce the dissonance between these conflicting desires via self-deception regarding their perception of fairness. The communication inherent in the Earnings Known-

Communication treatment may be a factor that reduces such cognitive dissonance (at least for those with high earnings).

\section{IV(c) - Regression Analysis}

While the analyses discussed above adjusted standard errors and hypothesis testing to account for the fact that each participant provides multiple observations, we can do this in a more formal matter. In particular, Table 2 analyzes the experimental treatments discussed above using individual fixed-effects regressions. The top panel shows the results from regressing the participant's proposed redistribution rule $p$ in a given round on his or her earnings quintile from that round. Moreover, given financial self-interest in the Earnings Known treatments actually implies that participants actually choose either complete redistribution $(p=1)$ or no redistribution $(p=0)$, the second and third panels show the results of analogous regressions with binary indicators for proposing no redistribution (i.e., the indicator equals 1 if $p=0$ and zero otherwise) and proposing complete redistribution (i.e., the indicator equals 1 if $p=1$ and zero otherwise) respectively. These are done as linear probability models using OLS, as this makes the coefficients directly interpretable and arguably imposes fewer assumptions in a fixedeffects setting than a maximum likelihood method such as a probit regression. However, the essential results are unchanged under probit regressions instead of OLS regressions (results available upon request). 
As can be seen in Table 2, in the Earnings Unknown treatment, a person's own earnings quintile appears to have an extremely modest impact on his/her proposed redistribution level relative to the Earnings Known - Base and Earnings Known Random treatments. For example, in the top panel where the dependent variable is the proposed redistribution rule $p$, the magnitude of the coefficient on Earnings Quintile in the Earnings Unknown treatment is less than 5 percent of the size of the coefficients on Earnings Quintile in the Earnings Known and Earnings Known-Random treatments. The coefficient on Earnings Quintile on proposed redistribution level in the Earnings Known - Communication treatment lies between the coefficient on Earnings Quintile in the Earnings Unknown and the two other Earnings Known treatments. Moreover, in the Earnings Unknown treatment, the coefficient on Earnings Quintile is actually positive (and statistically significantly so at the 10 percent level). In other words, in the Earnings Unknown treatment, higher earnings are actually slightly correlated with a higher level of proposed redistribution. Note however, that almost all of the explained variation is due to fixed-differences between individuals rather than changes in behavior within individuals. In the other treatments, the explained variation due to changes in behavior within individuals across rounds explains roughly as much of the overall variation as differences in behavior across individuals.

As can be seen in the bottom two panels of Table 2, these results are robust to using indicators for proposing no redistribution $(p=0)$ and proposing complete redistribution $(p=1)$ as the dependent variables. Specifically, the middle panel shows that an individual's earnings quintile in a given round is far more positively correlated with proposing no redistribution (i.e., $p=0$ ) in the Earnings Known and Earnings KnownRandom treatments than in the Earnings Unknown and Earnings Known-Communication treatments. The bottom panels shows that while an individual's earnings quintile in a given round is far more negatively correlated with proposing complete redistribution (i.e., $p=1)$ in the Earnings Known and Earnings Known-Random treatments than in the Earnings Unknown treatment, the correlation between earnings quintile and proposing complete redistribution is somewhere in the middle for the Earnings KnownCommunication treatment. And again, in the Earnings Unknown Treatment, almost all of the explained variation is explained by differences across individuals, while in the other 
treatments, a large part of the variation is explained by changes in behavior within individuals across rounds.

Instead of using fixed-effects regressions, Table 3 examines how earnings and various other personal characteristics are correlated with the proposed level of redistribution by regressing the proposed redistribution rule $p$ on Earnings Quintile and a variety of other personal characteristics (standard errors are clustered by individual to account for multiple observations per individual). These regression results again reveal that earnings outcomes are very strongly tied to proposed levels of redistribution for all of the Earnings Known treatments, but very weakly so for the Earnings Unknown treatment. Interestingly however, personal characteristics such as gender, political affiliation, and even tolerance for risk as revealed by a stated willingness to gamble, do not have any correlation with proposed redistribution levels. ${ }^{9}$ These findings are generally consistent with Esarey, Salmon, and Barrilleaux (2012a), in which they also find that self-reported economic ideology generally do not trump self-interest in a laboratory redistribution environment. ${ }^{10}$

In summary, the vast majority of participants in the Earnings Known treatments appear to be motivated by their own financial self-interest when proposing redistribution levels. However, there is a small but significant minority of participants who appear to be motivated by other concerns. As discussed above, one thing that seems to impact the willingness of individuals to choose a redistribution level that runs counter to their own financial self-interest is the ability of low earners and high earners to communicate with each other. Table 4 looks at what else potentially impacts such willingness to engage in behavior inconsistent with pure financial self-interest.

Specifically, Table 4 shows the results of regressions where an indicator for whether the participant proposed an "interior" or non-extreme redistribution level (i.e., $p$ strictly between 0 and 1)---an action not consistent with pure financial self-interest---is regressed on a variety of participant characteristics. As can be seen, none of the coefficients on gender, political affiliation, or risk-tolerance show statistically significant

\footnotetext{
${ }^{9}$ Specifically, subjects were asked what they would be willing to pay to participate in a coin flip gamble where they would win $\$ 100$ if the coin landed on heads and nothing if it landed on tails.

${ }^{10}$ Table A-1 in the Appendix shows that very similar conclusions are drawn when using "proposed no redistribution $(\mathrm{p}=0)$ " and "proposed full redistribution $(\mathrm{p}=1)$ " are used as the dependent variable.
} 
relationships with such "interior" proposals. Moreover, how much variation in earnings the participant experienced in the previous two rounds also did not have a statistically significant relationship with such behavior. ${ }^{11}$

However, looking at the top two rows of Table 4, we see significantly negative coefficients on "Amount above mean" and "Amount below mean" in the Earnings Known - Base and Earnings Known -Random treatments, which reveal that in these treatments, the closer a participant's earnings were to the mean the more likely he/she was to act in a manner not consistent with pure financial self-interest. By contrast, the small and statistically insignificant coefficients on "Amount above mean" and "Amount below mean" in the Earnings Unknown treatment show that how much a participant's earnings exceeded or fell short of mean earnings was unrelated to whether or not the individuals proposed an "interior" redistribution proposal (as should be expected given they are proposing before such information is known). Finally, the relatively large and statistically significant coefficient on "Amount below mean" in the Earnings Known Communication treatment shows that the more a participant's earnings fell short of the mean the less likely he/she was to propose less than complete redistribution, but in contrast to the other two Earnings Known treatments, the small and statistically insignificant coefficient on "Amount above mean" reveals that the more a participant's earnings exceeded the mean did not affect his or her likelihood to propose a strictly positive level of redistribution.

This finding can be seen even more starkly in Figure 6, which shows the fraction of individuals proposing an "interior" redistribution rule $p$---a $p$ strictly between zero and one---for the three Earnings Known treatments. Again, financial self-interest would always imply that those with earnings below the mean should propose $p=1$, while those with earnings above the mean should propose $p=0$, meaning any interior proposal is not consistent with pure financial self-interest. As can be seen, under each of the three treatments, such behavior inconsistent with pure financial self-interest peaks for those with earnings in the middle quintile of the distribution in their round, and falls monotonically with how far earnings are both above and below the mean. However, in

\footnotetext{
${ }^{11}$ In order to see if earnings variation in the previous rounds were correlated with proposed levels of redistribution, the regressions in Table 4 only use data from rounds 3-6.
} 
the Earnings Known - Communication treatment, this fall off in behavior inconsistent with pure financial self-interest for participants with earnings above the mean is very tempered relative to the other two treatments.

In general, the results from this experiment suggest that individuals generally see redistribution as a form of insurance. By and large, when given the chance, individuals propose a level of redistribution that maximizes their own financial self-interest. But, as shown by Table 4 and Figure 6, the relatively small number of participants who appear to be motivated by factors other than financial self-interest are primarily those who lose very little money by behaving in a manner at odds with pure monetary self-interest.

\section{V - Examining Experimental Implications Outside of the Lab}

While applying lab results such as these to settings outside of the lab is always quite speculative, it is important to at least consider the extent to which lab results can help further our understanding of the world outside the lab. One context in which to look at whether the findings from this experiment can help us understand behavior outside of the lab might be with respect to how preferences for redistribution evolve with age. Arguably, when a person first enters the labor market, he faces considerable uncertainty regarding his position in the income distribution over the next few years, as while he may know how his skill set has fared relative to others in school, he has less information regarding how that skill set will fare in the job market, and whether he will land and/or maintain a job that is a good fit for his skills. However, as an individual spends more time in the labor market, he obtains more information regarding how his skills fare relative to others in the labor market and what type of job he can obtain and maintain, so that by later in his career he arguably should become less uncertain about his position in the income distribution over the next few years.

To the extent to which it is true that people become more certain about their relative positions in the income distribution over the next few years as they age, then if preferences for redistribution are primarily driven by financial self-interest as the results of the above laboratory experiment suggest, preferences for redistribution should become more extreme as people age. To put in the context of the previous experiment, those doing financially well while young may still see an insurance role for redistribution to 
help mitigate future uncertainty, while older individuals doing financially well may feel sufficiently self-insured and therefore would be more likely to strongly oppose redistribution. On the other hand, the young who are doing financially poorly may be hesitant to be overly supportive of redistribution efforts as they think they may still achieve financial success in the future, while older individuals who are doing financially poorly see little incentive not to support substantial redistribution efforts.

To look at these hypotheses, I use data from the National Longitudinal Survey of Youth 1979 (NLSY79) to look at whether relative income uncertainty falls by age, and the $1980-2010$ General Social Survey (GSS) to then look at how preferences for redistribution evolve by age.

The NLSY79 is a survey project that started in 1979 with over twelve thousand 12-21 year old youth who have then been followed and resurveyed annually or biannually up to the present. One of the key data components of the survey is family income. I use such data to examine whether income uncertainty falls with age in the following manner. I first calculate each person's "income" each year (where "income" is defined as total family income divided by number of family members living in the household), and then determine each person's percentile in the overall income distribution for that year. I then determine each person's percentile in the income distribution at ages 23, 25, 45, and 47 (the oldest age for which this is possible). For each person with valid income data at each of these ages (5902 individuals), I compute the absolute change in income percentile for each person between age 23 and 25 , as well as the absolute change in income percentile between the age of 45 and 47 . To the extent that, on average, there are greater net changes in income percentile between ages 23 to 25 than there are between the ages of 45 and 47 would provide evidence consistent with the notion that relative income percentile uncertainty falls with age as hypothesized above.

My results show this to be true. Between the ages 23 and 25, individuals moved an average of 19 percentiles up or down in the earnings distribution, with the median person moving 13 percentiles. By contrast, between the ages of 45 and 47, individuals moved an average of only 10 percentiles up or down in the earnings distribution, with the median person moving only 6 percentiles. While it would be nice to calculate this statistic at even later ages, this simply isn't possible with the NLSY79 data. However, these 
results do seem to suggest there is less variation regarding an individual's place in the income distribution as he or she ages.

Given the result above, I now turn to the question of how preferences for redistribution evolve with age. As stated above, to look at this I use data from the General Social Survey (GSS). The GSS is a nationally representative survey of the U.S. non-child population conducted every one or two years since 1972. It is meant to track how Americans' behaviors and attitudes change over time and/or compare to other countries.

In addition to basic demographic information such as age, gender, education, and income, a variety of attitudinal questions are asked including one about preferences regarding the role of government in redistributing income. In particular, the primary question I use for this analysis was eqwlth, which asked:

Some people think that the government in Washington ought to reduce income differences between the rich and the poor, perhaps by raising the taxes of wealthy families or by giving income assistance to the poor. Others think that the government should not concern itself with reducing this income difference between the rich and the poor. Here is a card with a scale from 1 to 7 . Think of a score of 1 as meaning that the government ought to reduce income differences between rich and poor, and a score of 7 meaning that the government should not concern itself with reducing income differences. What score between 1 and 7 comes closest to the way you feel?

While not directly analogous to the redistribution proposals in the experiment discussed above, this question seems to have at least some of the same flavor.

As a first look at how support for or against government redistribution efforts evolve with age, I simply compare responses for those just starting their work life (ages 20-25) to those ending their work life (ages 60-65). Interestingly, the mean response to this eqwlth question was quite similar for those age 60-65 to those age 20-25 (3.77 vs. 3.50). However, Figure 7 shows that the distributions of responses to this question differ substantially across these two age groups. Those ages 60-65 are more likely than those ages 20-25 to answer one of the extreme choices of 1 or 7 . In both cases this difference is 
statistically significant at the $1 \%$ level, even when taking account of correlation within survey year (and using the more conservative two-sided test). While the difference across age groups with respect to the fraction answering 1 (government ought to reduce income differences between rich and poor) is quite small ( 0.17 for those age 20-25 vs. 0.22 for those age 60-65), the fraction of those age 60-65 answering 7 (government should not concern itself with reducing income differences) is well over twice that of those age 2025 ( 0.16 for those age $60-65$ vs. 0.07 for those age $20-25)$. Hence, preferences for or against redistribution appear to become more extreme with age, which is consistent with the laboratory findings to the extent one believes the above results that relative income uncertainty diminishes over time. Moreover, it does not appear that this is simply due to changes in preferences for redistribution across cohorts, as results are virtually unchanged when I do the analysis separately for the 1980-1989 waves and the 2000-2010 waves (results available upon request).

To analyze this issue in a broader way, I use GSS data for all respondents ages 18 and above to examine how preferences over redistribution vary with age in a regression setting. Specifically, Table 5 presents the results from several probit specifications. The dependent variable in specifications (1) - (3) equals one if the individual answered the eqwlth question with a 7 (the strongest possible opposition to government redistribution efforts) and zero otherwise, while the dependent variable in specifications (4) - (6) equals one if the individual answered the eqwlth question with a 1 (the strongest possible support for government redistribution efforts) and zero otherwise. Specifications (1) and (4) only control for age and year as right-hand side variables, specifications (2) and (5) further add income as a right-hand side variable, and finally specifications (3) and (6) further add race and gender indicators, a college education indictor, and indicators for liberal and conservative political affiliations (politically moderate is the excluded category). The numbers shown are the marginal effects calculated at the mean.

Looking first at the results in specifications (1) - (3) we see, not surprisingly, that those with higher income and conservative political views are more likely to voice extremely strong opposition to government supported redistribution than lower income and non-conservative individuals, while blacks, females, and liberals are less likely to voice extremely strong opposition to government supported redistribution than whites, 
males, and non-liberals. Notably for this study however, the coefficient on age is positive and significant in specifications (1) - (3), meaning regardless of what else is controlled for, aging is associated with being more likely to voice extremely strong opposition to government supported redistribution.

Looking at the results in specifications (4) - (6), we again find the expected results that those with higher income and conservative political views (as well as a college education) are less likely to voice extremely strong support for government supported redistribution than lower income and non-conservative individuals, while blacks, females, and liberals are more likely to voice extremely strong support for government supported redistribution than whites, males, and non-liberals. Again, most notable for this study, specifications (4) - (6) show that the coefficient on age is again positive and significant regardless of what else is controlled for, indicating that aging is also associated with a higher likelihood to voice extremely strong support for government redistribution efforts.

Overall, the probit regression results in Table 6 find considerable evidence that individuals become more extreme in their views with respect to government redistribution efforts as they age, even after controlling for income and political viewpoints. To the extent that uncertainty over subsequent relative income falls with age as suggested by the NLSY79 results, the finding that individuals support for or opposition to government redistribution efforts becomes more extreme as they age is certainly consistent with the earlier laboratory results.

\section{VI - Summary and Conclusion}

The results of the experiment described in this paper show that individuals' revealed preferences for the amount of redistribution of earnings they would like to see implemented depend substantially on the degree to which they know where they will lie in the earnings distribution. When participants were asked to propose a level of redistribution before they knew where they were going to end up in the earnings distribution, the vast majority of participants propose a positive but relatively modest amount of redistribution. By contrast, when participants were asked to propose a level of redistribution after they knew where they ended up in the earnings distribution, the vast 
majority (roughly seventy percent) of participants proposed either no redistribution or complete redistribution (i.e., perfect payoff equality), depending on whether they ended up in the upper half or the lower half of the earnings distribution. This behavior did not seem to be affected by whether earnings were partially earned through skill at answering questions or determined completely at random.

As argued above, this transition to bimodal preferences over redistribution as earnings uncertainty diminishes is generally consistent with financial self-interest being the primary motivator for redistribution. Indeed, to the extent one believes that uncertainty over one's position in income distribution in subsequent years falls with age (which is consistent with evidence from the National Longitudinal Survey of Youth), this might help explain the findings from the General Social Survey that as individuals age, individuals become more extreme in their stated support for or opposition to government redistribution efforts. However, while behavior consistent with such financial self-interest was observed from roughly seventy percent of the participants in the lab experiment, there was the non-negligible remaining thirty percent who did not appear to act with complete financial self-interest.

Interestingly, most of this group who acted without complete financial selfinterest was made up of those with the least to lose financially by doing so. In other words, people generally were only willing to engage in behavior that financially benefited others when it was cheaper to do so. However, this fraction of individuals who acted in a manner not consistent with pure financial self-interest grew to fifty-five percent when anonymous communication was allowed after earnings outcomes were known but before redistribution proposals were made. Almost all of the increase in behavior that was inconsistent with financial self-interest came from individuals with relatively high earnings who proposed relatively high levels of redistribution, rather than from relatively low earning individuals who proposed lower levels of redistribution.

In conclusion, the results of this laboratory experiment described in this paper suggest that in an income tax and transfer context, individuals' motivations for redistribution primarily appear to be a means to insure themselves against bad outcomes-a finding that appears consistent with how stated preferences for redistribution evolve with age outside the lab. However, at least in the laboratory, for many people, this purely 
financially self-interested motivation for redistribution appears to be somewhat fragile, as even a small amount of anonymous communication can make the high earners more willing to redistribute some of their earnings to lower earners. 


\section{VIII - References}

Alesina, Alberto and Eliana La Ferrara. (2005). "Preferences for Redistribution in the Land of Opportunities." Journal of Public Economics 89: 897-931.

Andreoni, James. (2007). "Giving Gifts to Groups: How Altruism Depends on the Number of Recipients." Journal of Public Economics 91: 1731-1749.

Bardsley, Nicholas. (2008). "Dictator Game Giving: Altruism or Artefact?" Experimental Economics 11: 122-133.

Camerer, Colin. (2003). Behavioral Game Theory: Experiments in Strategic Interaction. Princeton: Princeton University Press.

Cappelen, Alexander, Astri Drange Hole, Erik O Sorensen, and Bertil Tungodden. (2007). "The Pluralism of Fairness Ideals: An Experimental Approach.” The American Economic Review 97(3): 818-827.

Charness, Gary and Martin Dufwenberg. (2006). "Promises and Partnership." Econometrica 74(6): 1579-1601.

Corneo, Giacomo and Christina Fong. (2008). "What's the Monetary Value of Distributive Justice?” Journal of Public Economics 92(1): 289-308.

Corneo, Giacomo and Hans Peter Gruner. (2002). "Individual Preferences for Political Redistribution." Journal of Public Economics 83: 83-107.

Durante, Ruben, Louis Putterman, and Joel van der Weele. (2014). "Preferences for Redistribution and Perception of Fairness: An Experimental Study." Journal of the European Economic Association 12(4): 1059-1086.

Eckel, Catherine C. and Philip J. Grossman. (1996). "Altruism in Anonymous Dictator Games." Games and Economic Behavior 16: 181-191.

Esarey, Justin, Timothy Salmon, and Charles Barrilleux. (2012a). "What Motivates Political Preferences? Self-Interest, Ideology, and Fairness in a Laboratory Democracy." Economic Inquiry 50(3): 604-624.

----. (2012b). "Social Insurance and Income Redistribution in a Laboratory

Environment." Political Research Quarterly 65(3): 685-698.

Fong, Christina. (2001). "Social Preferences, Self-Interest, and the Demand for Redistribution." Journal of Public Economics 82: 225-246.

Frolich, Norman, Joe A. Oppenheimer, and Cheryl L. Eavey. (1987a). "Laboratory Results on Rawls' Distributive Justice." British Journal of Political Science 17(1): 1-21. 
Frolich, Norman, Joe A. Oppenheimer, and Cheryl L. Eavey. (1987b). "Choices of Principles of Distributive Justice in Experimental Groups." American Journal of Political Science 31(3): 606-636.

Frolich, Norman and Joe A. Oppenheimer. (1990). "Choosing Justice in Experimental Democracies with Production." American Political Science Review 84(2): 461-477.

Harsanyi, John C. (1955). "Cardinal Welfare, Individualistic Ethics, and Interpersonal Comparisons of Utility." Journal of Political Economy 63: 309-321.

Harsanyi, John C. (1975). "Review: Can the Maximin Principle Serve as a Basis for Morality? A Critique of John Rawls' Theory." American Political Science Review 69(2): 594-606.

Hayashi, Andrew T. (2013). "Occasionally Libertarian: Experimental Evidence of SelfServing Omission Bias.” Journal of Law, Economics, and Organization 29(3): 711-733.

Hoffman, Elizabeth, Kevin McCabe, and Vernon L. Smith. (1996). "Social Distance and Other-Regarding Behavior in Dictator Games." American Economic Review 86(3): 653660.

Kerr, William R. (2014). "Income Inequality and Social Preferences for Redistribution and Compensation Differentials.” Journal of Monetary Economics 66: 25-48.

Klor, Esteban F. and Moses Shayo. (2010). "Social Identity and Preferences over Redistribution." Journal of Public Economics 94: 269-278.

Konow, James. (2000). "Fair Shares: Accountability and Cognitive Dissonance in Allocation Decisions." American Economic Review 90(4): 1072-1092.

Krawczyk, Michal. (2010). "A Glimpse Through the Veil of Ignorance: Equality of Opportunity and Support or Redistribution." Journal of Public Economics 94: 131-141.

Levitt, Steven and John List. (2007). "What Do Laboratory Experiments Measuring Social Preferences Reveal About the Real World?" Journal of Economic Perspectives 21(2): 153-174.

List, John (2007), "On the Interpretation of Giving in Dictator Games." Journal of Political Economy 115(3): 482-493.

Ravallion, Martin and Michael Lokshin. (2000). "Who Wants to Redistribute? The Tunnel Effect in 1990s Russia." Journal of Public Economics 76: 87-104.

Rawls, John. (1971). A Theory of Justice. Cambridge: Harvard University Press. 
-------. (2001). Rawls Justice as Fairness: A Restatement. Cambridge: Harvard University Press.

Rutstrom, E. Elizabeth and Melonie Williams. (2000). "Entitlements and Fairness: An Experimental Study of Distributive Preferences." Journal of Economic Behavior and Organization 43: 75-89.

Schildberg-Horisch, Hannah. (2010). "Is the Veil of Ignorance Only a Concept of Risk?" Journal of Public Economics 94(11-12): 1062-1066.

Yamamori, Tetsuo, Kazuhiko Kato, Toshiji Kawagoe, and Akihiko Matsui. (2008).

"Voice Matters in a Dictator Game." Experimental Economics 11: 336-343. 


\section{Figure 1 - Summary of Game Procedures under Primary Treatments}

\section{Earnings Known Treatment}

1 - Participants are told a new round is commencing.

2 - Participants learn their rate of return for each correctly answered question and observe what type of questions will be asked that round.

3 - Participants answer as many questions as they can in four minutes.

4 - Participants learn their earnings (in tokens) for that round, the mean earnings among all participants in that round, and where their earnings lay in the overall earnings distribution for that round.

5 - Participants choose a redistribution level p via an electronic slider.

6 - Participants learn what redistribution level $p$ was implemented and their final payoff for that round given their earnings and the implemented redistribution level $p$.

7 - A new rounds starts.

\section{Earnings Unknown Treatment}

1 - Participants are told a new round is commencing.

2 - Participants choose a redistribution level $p$ via an electronic slider.

3 - Participants learn their rate of return for each correctly answered question and observe what type of questions will be asked that round.

4 - Participants answer as many questions as they can in four minutes.

5 - Participants learn their earnings (in tokens) for that round, the mean earnings among all participants in that round, and where their earnings lay in the overall earnings distribution for that round.

6 - Participants learn what redistribution level $p$ was implemented and their final payoff for that round given their earnings and the implemented redistribution level $p$. $7-$ A new rounds starts. 


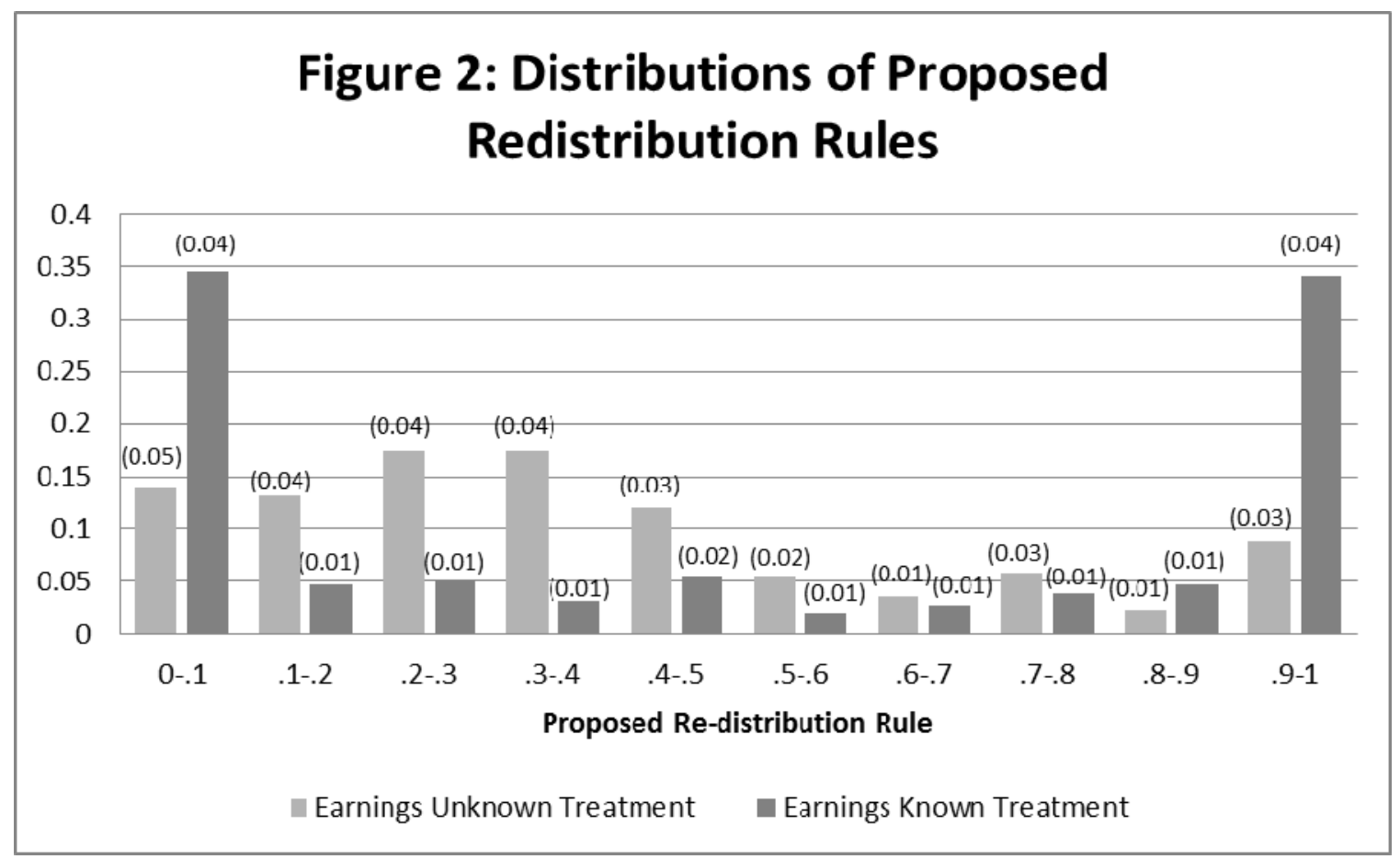

Note: Each treatment consisted of 43 distinct individuals each playing six rounds of the same treatment. Each individual only participated in one treatment. Standard errors, adjusted for taking into account multiple observations per individual, are shown in parentheses. A joint F-test taking into account multiple observations per individual rejects the equality of these two distributions at the 0.0001 level. 


\section{Figure 3a: Distribution of Proposed Redistribution Rules - Below vs. Above Mean (Earnings Known Treatment Only)}

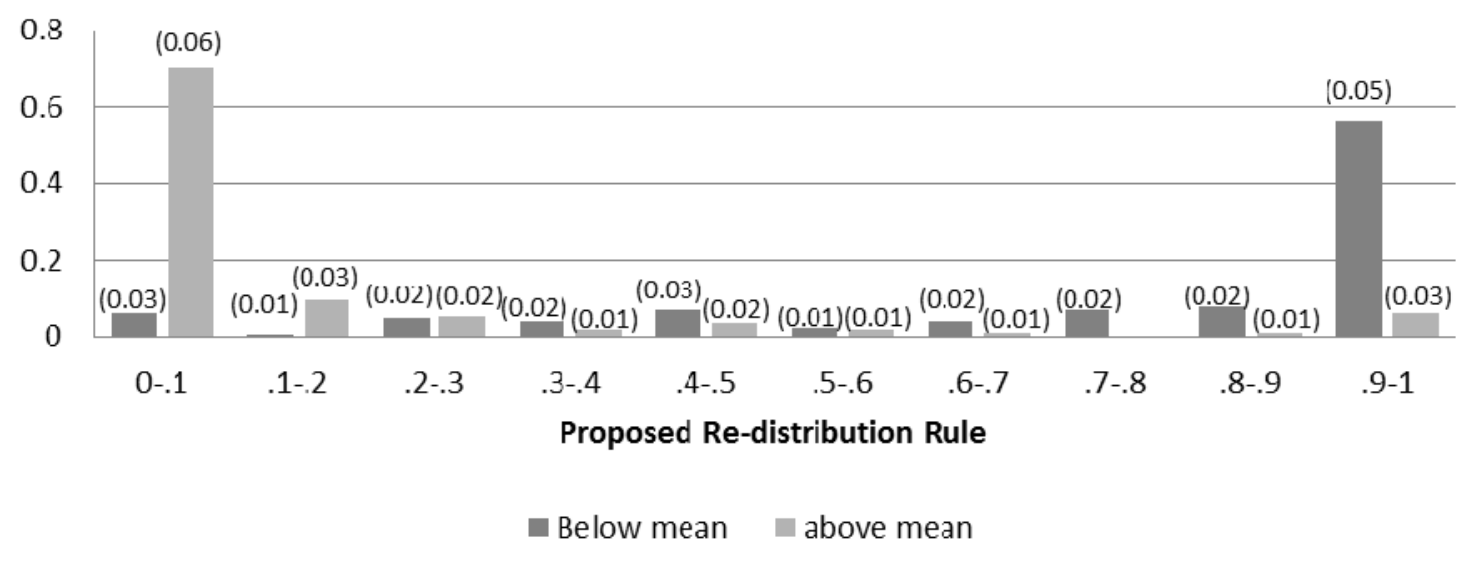

Note: Standard errors, adjusted for taking into account multiple observations per individual, are shown in parentheses. A joint F-test taking into account multiple observations per individual rejects the equality of these two distributions at the 0.0001 level.

\section{Figure 3b: Distribution of Proposed Redistribution Rules - Below vs. Above Mean (Earnings Unknown Treatment Only)}

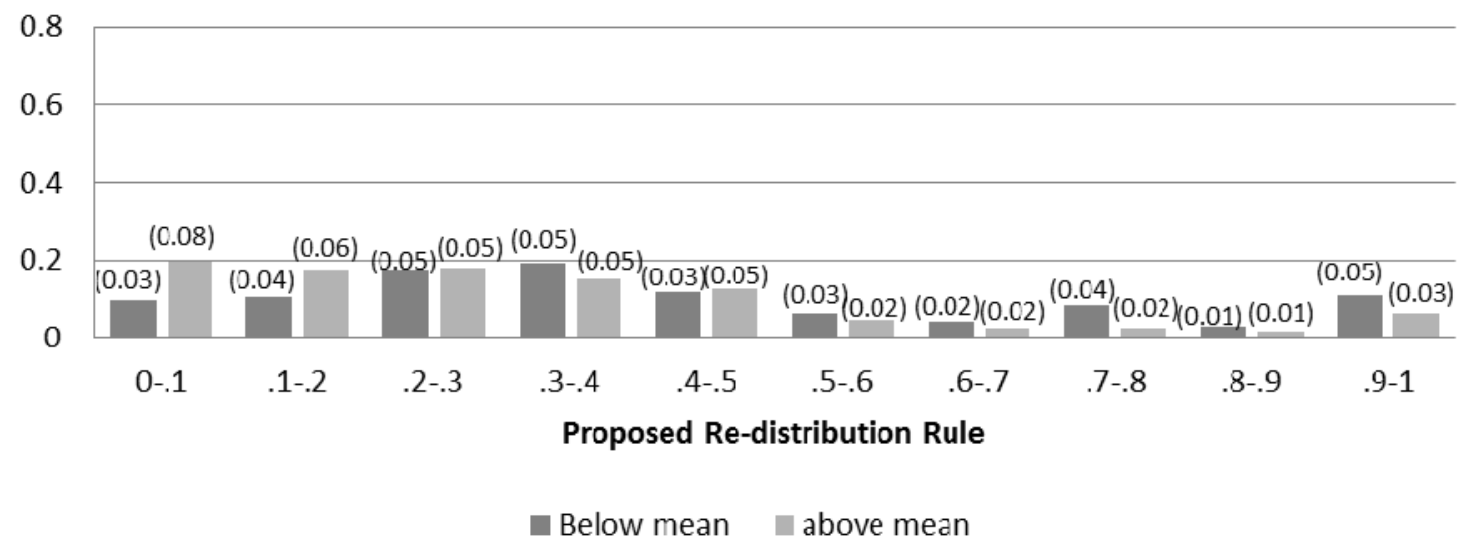

Note: Standard errors, adjusted for taking into account multiple observations per individual, are shown in parentheses. A joint F-test taking into account multiple observations per individual cannot reject the equality of these two distributions at even the 0.15 level ( $\mathrm{p}$-val 0.50). 
Table 1: Per Round Earnings and Correct Answers Per Person, by Treatment

\begin{tabular}{|c|c|c|c|c|}
\hline & \multicolumn{2}{|c|}{ Earnings (tokens) } & \multicolumn{2}{|c|}{ Correct Answers } \\
\hline & $\begin{array}{l}\text { Earnings } \\
\text { Unknown }\end{array}$ & $\begin{array}{c}\text { Earnings } \\
\text { Known }\end{array}$ & $\begin{array}{l}\text { Earnings } \\
\text { Unknown }\end{array}$ & $\begin{array}{c}\text { Earnings } \\
\text { Known }\end{array}$ \\
\hline mean & 89.43 & 92.9 & 9.83 & 9.84 \\
\hline 25th percentile & 54 & 56 & 7 & 7 \\
\hline 50th percentile & 81 & 84 & 9 & 9 \\
\hline 75th percentile & 120 & 121 & 12 & 12 \\
\hline obs & 258 & 258 & 258 & 258 \\
\hline \multicolumn{5}{|l|}{ Early Rounds (1-3) } \\
\hline mean & 88.7 & 93.0 & 9.0 & 9.7 \\
\hline 25th percentile & 48 & 56 & 6 & 7 \\
\hline 50th percentile & 80 & 88 & 9 & 9 \\
\hline 75th percentile & 120 & 128 & 11 & 12 \\
\hline obs & 129 & 129 & 129 & 129 \\
\hline \multicolumn{5}{|l|}{ Late Rounds (4-6) } \\
\hline mean & 90.1 & 92.7 & 10.7 & 10 \\
\hline 25th percentile & 56 & 54 & 8 & 7 \\
\hline 50th percentile & 81 & 84 & 10 & 9 \\
\hline 75th percentile & 114 & 120 & 13 & 12 \\
\hline obs & 129 & 129 & 129 & 129 \\
\hline num of participants & 43 & 43 & 43 & 43 \\
\hline
\end{tabular}




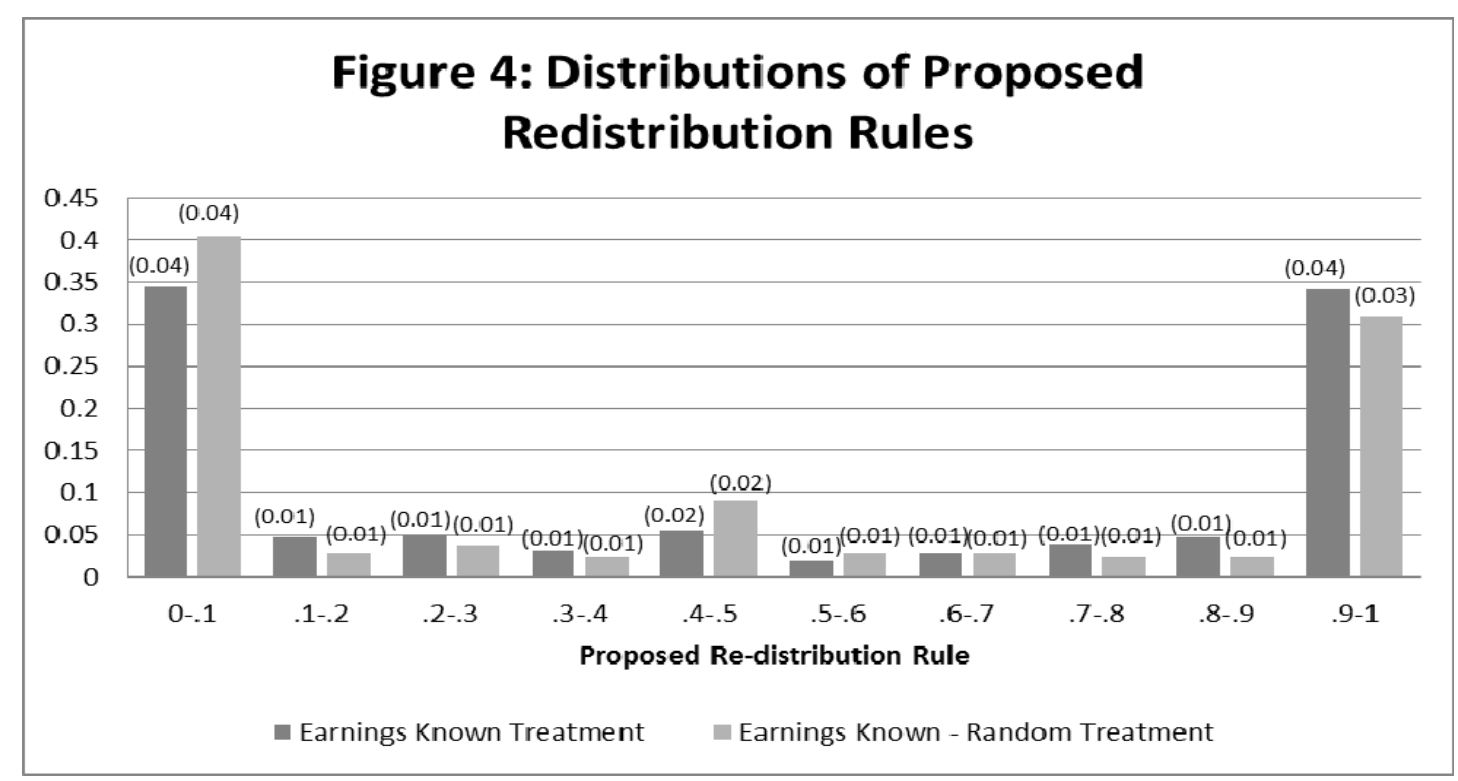

Note: The Earnings Known treatment consisted of 43 individuals, and the Earnings KnownRandom treatment consisted of 35 individuals, each playing six rounds of the same treatment. Each individual only participated in one treatment. Standard errors, adjusted for taking into account multiple observations per individual, are shown in parentheses. A joint F-test taking into account multiple observations per individual cannot reject the equality of these two distributions at the 0.15 level (p-val 0.49).

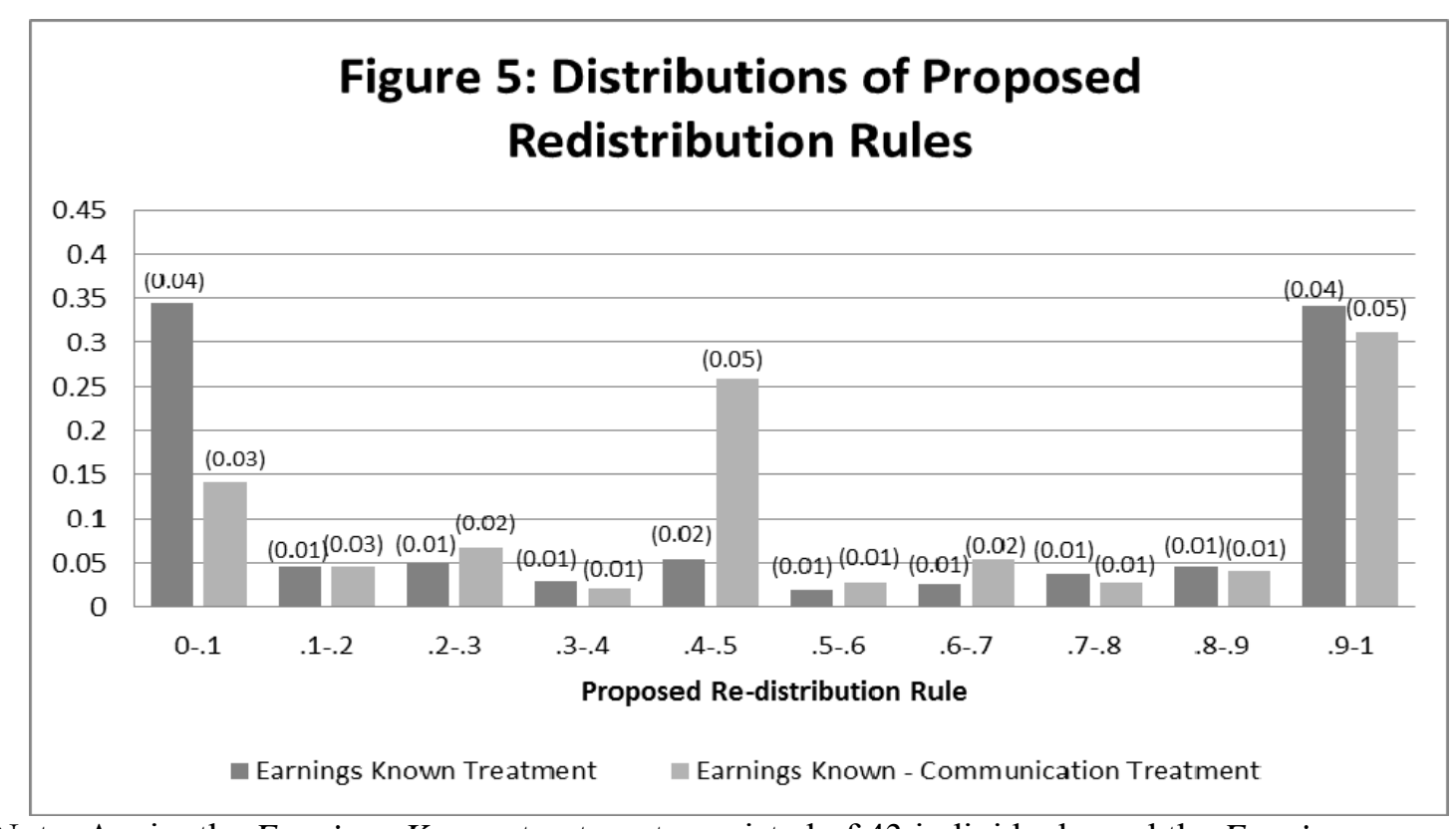

Note: Again, the Earnings Known treatment consisted of 43 individuals, and the Earnings Known-Communication treatment consisted of 40 individuals, each playing six rounds of the same treatment. Each individual only participated in one treatment. Standard errors, adjusted for taking into account multiple observations per individual, are shown in parentheses. A joint F-test, taking into account multiple observations per individual, can reject the equality of these two distributions at the 0.005 level. 
Table 2: Individual Fixed-Effects Regression Analysis

\begin{tabular}{|c|c|c|c|c|}
\hline & \multicolumn{4}{|c|}{ Treatment } \\
\hline & $\begin{array}{l}\text { Earnings } \\
\text { Unknown }\end{array}$ & $\begin{array}{c}\text { Earnings } \\
\text { Known - Base }\end{array}$ & $\begin{array}{l}\text { Earnings } \\
\text { Known - } \\
\text { Random }\end{array}$ & $\begin{array}{c}\text { Earnings } \\
\text { Known - } \\
\text { Communication }\end{array}$ \\
\hline \multicolumn{5}{|c|}{ Dependent Variable: Proposed Redistribution Rule (p) } \\
\hline Earnings Quintile & $\begin{array}{c}0.0172 * \\
(0.00883)\end{array}$ & $\begin{array}{c}-0.228 * * * \\
(0.0165)\end{array}$ & $\begin{array}{c}-0.249 * * * \\
(0.0165)\end{array}$ & $\begin{array}{c}-0.151^{* * *} \\
(0.0192)\end{array}$ \\
\hline Constant & $\begin{array}{c}0.358 * * * \\
(0.0410)\end{array}$ & $\begin{array}{l}1.157^{* * * *} \\
(0.0454)\end{array}$ & $\begin{array}{l}1.202^{* * *} \\
(0.0594)\end{array}$ & $\begin{array}{l}1.040 * * * \\
(0.0597)\end{array}$ \\
\hline $\begin{array}{l}\text { R-squared: } \text { within } \\
\text { between }\end{array}$ & $\begin{array}{l}0.04 \\
0.31\end{array}$ & $\begin{array}{l}0.53 \\
0.59\end{array}$ & $\begin{array}{l}0.71 \\
0.59\end{array}$ & $\begin{array}{l}0.39 \\
0.39\end{array}$ \\
\hline \multicolumn{5}{|c|}{ Dependent Variable: Proposed No Redistribution $(p=0)$} \\
\hline Earnings Quintile & $\begin{array}{l}0.000811 \\
(0.00662)\end{array}$ & $\begin{array}{c}0.222 * * * \\
(0.0179)\end{array}$ & $\begin{array}{l}0.250 * * * \\
(0.0151)\end{array}$ & $\begin{array}{c}0.0982 * * * \\
(0.0207)\end{array}$ \\
\hline Constant & $\begin{array}{l}0.114 * * \\
(0.0449)\end{array}$ & $\begin{array}{c}-0.310 * * * \\
(0.0445)\end{array}$ & $\begin{array}{c}-0.397 * * * \\
(0.0362)\end{array}$ & $\begin{array}{c}-0.163 * * * \\
(0.0394)\end{array}$ \\
\hline $\begin{array}{l}\text { R-squared: within } \\
\text { between }\end{array}$ & $\begin{array}{c}0.001 \\
0.23\end{array}$ & $\begin{array}{l}0.44 \\
0.41\end{array}$ & $\begin{array}{l}0.58 \\
0.59\end{array}$ & $\begin{array}{l}0.20 \\
0.04\end{array}$ \\
\hline \multicolumn{5}{|c|}{ Dependent Variable: Proposed Full Redistribution $(p=1)$} \\
\hline Earnings Quintile & $\begin{array}{c}0.0270 * * \\
(0.0119)\end{array}$ & $\begin{array}{c}-0.185^{* * *} \\
(0.0221)\end{array}$ & $\begin{array}{c}-0.219 * * * \\
(0.0227)\end{array}$ & $\begin{array}{c}-0.149 * * * \\
(0.0246)\end{array}$ \\
\hline Constant & $\begin{array}{c}0.0115 \\
(0.0409)\end{array}$ & $\begin{array}{c}0.872 * * * \\
(0.0754)\end{array}$ & $\begin{array}{l}0.963 * * * \\
(0.0950)\end{array}$ & $\begin{array}{c}0.757^{* * *} \\
(0.0988)\end{array}$ \\
\hline $\begin{array}{l}\text { R-squared: within } \\
\text { between }\end{array}$ & $\begin{array}{l}0.05 \\
0.12\end{array}$ & $\begin{array}{l}0.27 \\
0.40\end{array}$ & $\begin{array}{l}0.51 \\
0.14\end{array}$ & $\begin{array}{l}0.24 \\
0.21\end{array}$ \\
\hline Observations & 258 & 258 & 210 & 240 \\
\hline Number of persons & 43 & 43 & 35 & 40 \\
\hline
\end{tabular}


Table 3: Regression Analysis (OLS) - Including participant characteristics

\begin{tabular}{|c|c|c|c|c|}
\hline & \multicolumn{4}{|c|}{ Treatment } \\
\hline & $\begin{array}{l}\text { Earnings } \\
\text { Unknown }\end{array}$ & $\begin{array}{l}\text { Earnings } \\
\text { Known - } \\
\text { Base }\end{array}$ & $\begin{array}{c}\text { Earnings } \\
\text { Known - Random }\end{array}$ & $\begin{array}{c}\text { Earnings } \\
\text { Known - } \\
\text { Communication }\end{array}$ \\
\hline \multicolumn{5}{|c|}{ Dependent Variable: Proposed Redistribution Rule (p) } \\
\hline Earnings Quintile & $\begin{array}{c}-0.0384 * * \\
(0.0184)\end{array}$ & $\begin{array}{c}-0.229 * * * \\
(0.0172)\end{array}$ & $\begin{array}{c}-0.251^{* * *} \\
(0.0176)\end{array}$ & $\begin{array}{c}-0.153^{* * *} \\
(0.0198)\end{array}$ \\
\hline round & $\begin{array}{c}0.0127 \\
(0.00772)\end{array}$ & $\begin{array}{l}0.0201 * \\
(0.0108)\end{array}$ & $\begin{array}{l}0.00913 \\
(0.0108)\end{array}$ & $\begin{array}{l}0.0181^{* *} \\
(0.00886)\end{array}$ \\
\hline female & $\begin{array}{c}0.0103 \\
(0.0793)\end{array}$ & $\begin{array}{r}-0.00872 \\
(0.0503)\end{array}$ & $\begin{array}{l}-0.0321 \\
(0.0417)\end{array}$ & $\begin{array}{c}0.0336 \\
(0.0468)\end{array}$ \\
\hline politically independent & $\begin{array}{l}-0.0925 \\
(0.145)\end{array}$ & $\begin{array}{c}0.0438 \\
(0.0717)\end{array}$ & $\begin{array}{c}0.0349 \\
(0.0398)\end{array}$ & $\begin{array}{c}0.158 \\
(0.0942)\end{array}$ \\
\hline politically conservative & $\begin{array}{l}-0.0508 \\
(0.0793)\end{array}$ & $\begin{array}{c}0.0122 \\
(0.0359)\end{array}$ & $\begin{array}{r}-0.00228 \\
(0.0672)\end{array}$ & $\begin{array}{c}0.0327 \\
(0.0395)\end{array}$ \\
\hline willingness to gamble & $\begin{array}{c}0.00156 \\
(0.00140)\end{array}$ & $\begin{array}{c}-0.000188 \\
(0.000641)\end{array}$ & $\begin{array}{c}0.00144 * \\
(0.000840)\end{array}$ & $\begin{array}{c}-0.000669 \\
(0.000791)\end{array}$ \\
\hline Constant & $\begin{array}{c}0.447^{* * *} \\
(0.112)\end{array}$ & $\begin{array}{c}1.093 * * * \\
(0.0848)\end{array}$ & $\begin{array}{c}1.149 * * * \\
(0.107)\end{array}$ & $\begin{array}{c}0.952 * * * \\
(0.0806)\end{array}$ \\
\hline R-squared & 0.082 & 0.553 & 0.695 & 0.429 \\
\hline Observations & 252 & 258 & 204 & 234 \\
\hline
\end{tabular}

Note: Robust standard errors clustered by individuals in parentheses. ${ }^{* * *}$ indicates significance at $1 \%$ level, $* *$ indicates significance at $5 \%$ level, $*$ indicates significance at $10 \%$ level. 
Table 4: Regression Analysis (OLS) - Non-extreme Redistribution Proposals

\begin{tabular}{|c|c|c|c|c|}
\hline & \multicolumn{4}{|c|}{ Treatment } \\
\hline & $\begin{array}{l}\text { Earnings } \\
\text { Unknown }\end{array}$ & $\begin{array}{c}\text { Earnings } \\
\text { Known - } \\
\text { Base }\end{array}$ & $\begin{array}{c}\text { Earnings } \\
\text { Known - } \\
\text { Rand }\end{array}$ & $\begin{array}{c}\text { Earnings } \\
\text { Known - } \\
\text { Communication }\end{array}$ \\
\hline \multicolumn{5}{|c|}{ Dependent Variable: $=1$ if $0<p<1$} \\
\hline Amount above mean & $\begin{array}{r}-0.00232 \\
(0.0171)\end{array}$ & $\begin{array}{c}-0.0408^{* * *} \\
(0.0119)\end{array}$ & $\begin{array}{c}-0.0892^{* * *} \\
(0.0184)\end{array}$ & $\begin{array}{l}-0.0179 \\
(0.0138)\end{array}$ \\
\hline Amount below mean & $\begin{array}{c}0.0145 \\
(0.0238)\end{array}$ & $\begin{array}{c}-0.0526 * * * \\
(0.0182)\end{array}$ & $\begin{array}{c}-0.0597 * * * \\
(0.0182)\end{array}$ & $\begin{array}{c}-0.0712^{* * *} \\
(0.0188)\end{array}$ \\
\hline Earnings diff. in prev. two rounds & $\begin{array}{l}-0.0427 \\
(0.0338)\end{array}$ & $\begin{array}{l}0.00681 \\
(0.0321)\end{array}$ & $\begin{array}{c}0.0256 \\
(0.0348)\end{array}$ & $\begin{array}{l}0.00340 \\
(0.0407)\end{array}$ \\
\hline round & $\begin{array}{l}-0.0358 \\
(0.0320)\end{array}$ & $\begin{array}{c}0.0284 \\
(0.0413)\end{array}$ & $\begin{array}{c}0.0338 \\
(0.0458)\end{array}$ & $\begin{array}{l}0.00836 \\
(0.0400)\end{array}$ \\
\hline female & $\begin{array}{l}0.0501 \\
(0.132)\end{array}$ & $\begin{array}{l}0.0725 \\
(0.111)\end{array}$ & $\begin{array}{l}-0.0236 \\
(0.0881)\end{array}$ & $\begin{array}{c}0.000160 \\
(0.131)\end{array}$ \\
\hline politically independent & $\begin{array}{c}-0.256 \\
(0.289)\end{array}$ & $\begin{array}{l}0.0443 \\
(0.174)\end{array}$ & $\begin{array}{l}-0.104 \\
(0.126)\end{array}$ & $\begin{array}{l}-0.115 \\
(0.116)\end{array}$ \\
\hline politically conservative & $\begin{array}{l}-0.137 \\
(0.149)\end{array}$ & $\begin{array}{c}0.116 \\
(0.112)\end{array}$ & $\begin{array}{c}-0.223^{* *} \\
(0.101)\end{array}$ & $\begin{array}{l}0.0122 \\
(0.162)\end{array}$ \\
\hline willingness to gamble & $\begin{array}{l}0.000585 \\
(0.00253)\end{array}$ & $\begin{array}{l}-0.00109 \\
(0.00113)\end{array}$ & $\begin{array}{l}-0.00283 \\
(0.00208)\end{array}$ & $\begin{array}{l}-0.00345 \\
(0.00210)\end{array}$ \\
\hline Constant & $\begin{array}{c}0.959 * * * \\
(0.198)\end{array}$ & $\begin{array}{c}0.253 \\
(0.255)\end{array}$ & $\begin{array}{c}0.471 * * \\
(0.230)\end{array}$ & $\begin{array}{c}0.773 * * * \\
(0.248)\end{array}$ \\
\hline R-squared & 0.071 & 0.129 & 0.246 & 0.165 \\
\hline Observations & 126 & 129 & 102 & 117 \\
\hline
\end{tabular}

Note: Robust standard errors clustered by individuals in parentheses. ${ }^{* * *}$ indicates significance at $1 \%$ level, ${ }^{* *}$ indicates significance at $5 \%$ level, $*$ indicates significance at $10 \%$ level. 


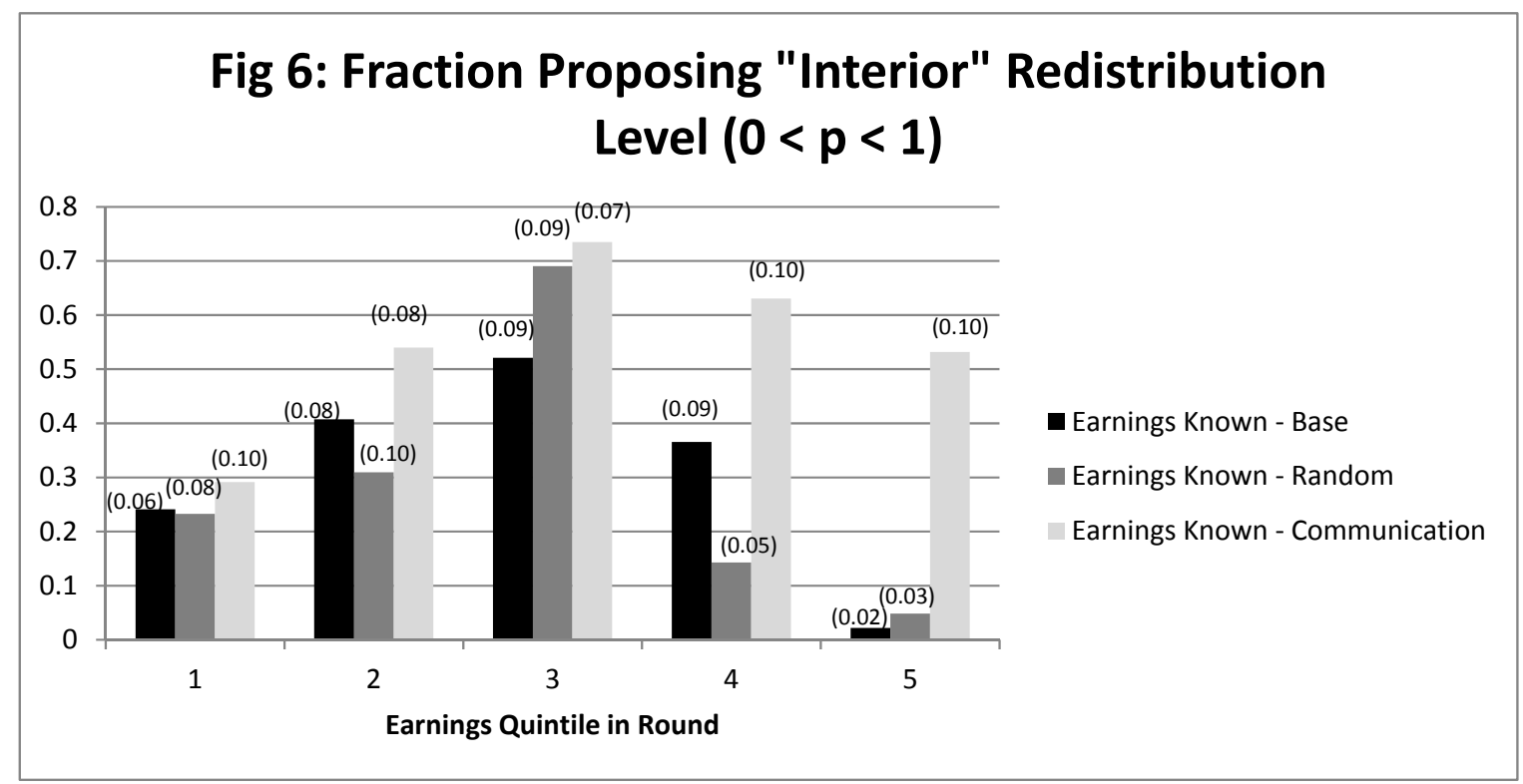

Note: Standard errors, adjusted for taking into account multiple observations per individual, are shown in parentheses. 


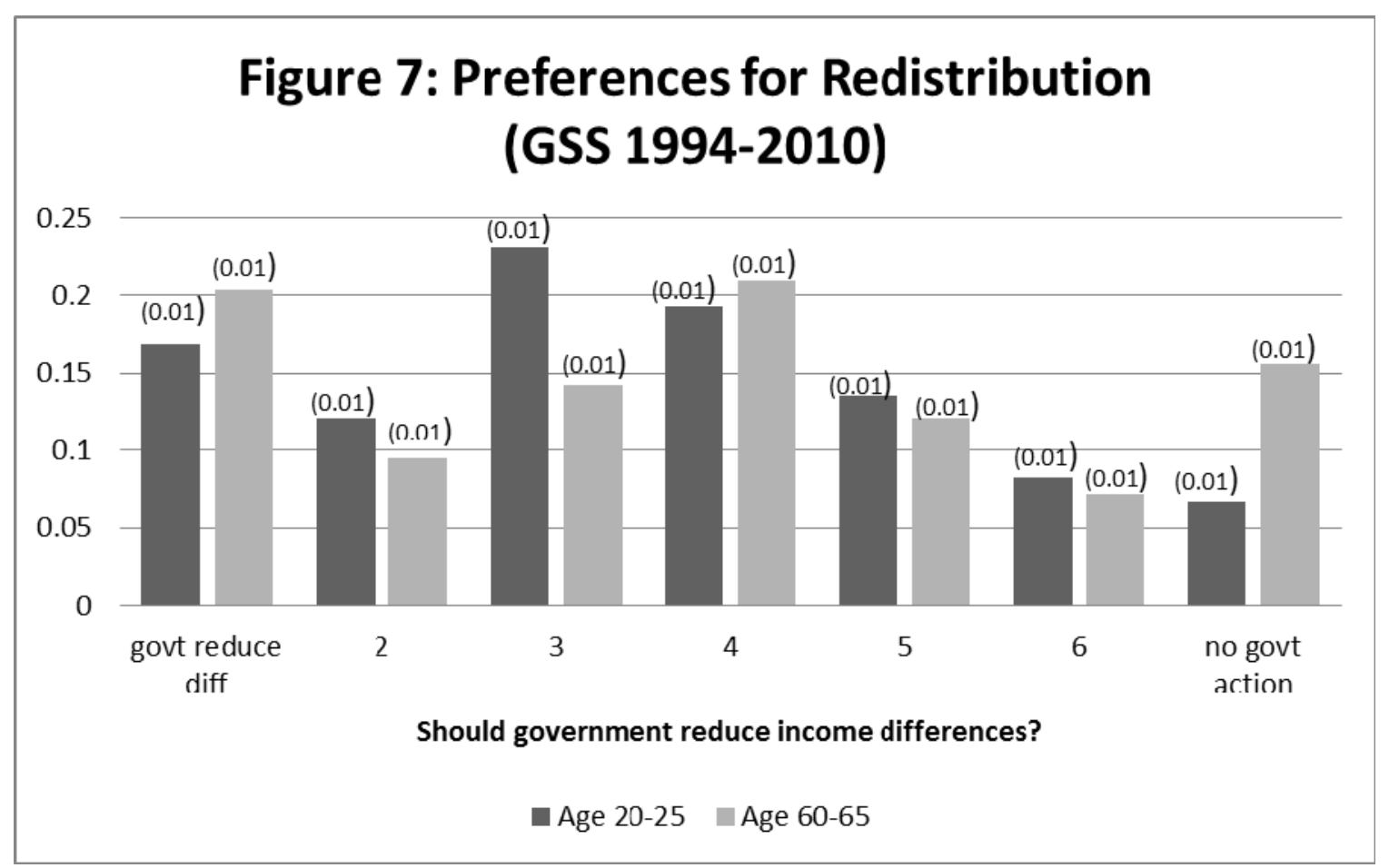

Note: Standard errors, clustered by year, are shown in parentheses. A joint F-test can reject the equality of these two distributions at the 0.005 level. 
Table 5 - Probit Regression Results from GSS

Dependent Variable

$=1$ if think no role for gov't = 1 if think large role for gov't redistribution

(i.e., eqwlth $=7$ ) redistribution

(1)

(2) (i.e., eqwlth = 1)

(3)

(5)

(6)

\section{(4)}

(5) (6)

\begin{tabular}{|c|c|c|c|c|c|c|}
\hline age & $\begin{array}{c}0.015^{* * *} \\
(0.001)\end{array}$ & $\begin{array}{c}0.017^{* * *} \\
(0.001)\end{array}$ & $\begin{array}{c}0.013^{* * *} \\
(0.001)\end{array}$ & $\begin{array}{c}0.006 * * * \\
(0.001)\end{array}$ & $\begin{array}{c}0.004^{* * *} \\
(0.001)\end{array}$ & $\begin{array}{c}0.007 * * * \\
(0.001)\end{array}$ \\
\hline year & $\begin{array}{c}0.000 \\
(0.000)\end{array}$ & $\begin{array}{c}-0.001 * * \\
(0.000)\end{array}$ & $\begin{array}{c}-0.001 * * * \\
(0.000)\end{array}$ & $\begin{array}{l}-0.000 \\
(0.000)\end{array}$ & $\begin{array}{c}0.000 \\
(0.000)\end{array}$ & $\begin{array}{c}0.000 \\
(0.000)\end{array}$ \\
\hline income & & $\begin{array}{c}0.011^{* * *} \\
(0.001)\end{array}$ & $\begin{array}{c}0.009 * * * \\
(0.001)\end{array}$ & & $\begin{array}{c}-0.020 * * * \\
(0.001)\end{array}$ & $\begin{array}{c}-0.014^{* * *} \\
(0.001)\end{array}$ \\
\hline black & & & $\begin{array}{c}-0.054 * * * \\
(0.005)\end{array}$ & & & $\begin{array}{c}0.110 * * * \\
(0.008)\end{array}$ \\
\hline female & & & $\begin{array}{c}-0.044 * * * \\
(0.004)\end{array}$ & & & $\begin{array}{c}0.015^{* * *} \\
(0.005)\end{array}$ \\
\hline college & & & $\begin{array}{l}-0.001 \\
(0.005)\end{array}$ & & & $\begin{array}{c}-0.086 * * * \\
(0.006)\end{array}$ \\
\hline liberal & & & $\begin{array}{c}-0.035 * * * \\
(0.006)\end{array}$ & & & $\begin{array}{c}0.120 * * * \\
(0.009)\end{array}$ \\
\hline conservative & & & $\begin{array}{c}0.125^{* * *} \\
(0.007)\end{array}$ & & & $\begin{array}{c}-0.022 * * * \\
(0.007)\end{array}$ \\
\hline Observations & 26,359 & 23,754 & 23,754 & 26,359 & 23,754 & 23,754 \\
\hline
\end{tabular}

Note: Marginal effects computed at the mean are shown. Standard errors in parentheses. ${ }^{* * *}$ indicates significance at $1 \%,{ }^{* *}$ significance at $5 \%$. 


\section{APPENDICIES}

Appendix 1 - Examples of questions asked in "task" completion component of game

(i) Examples of GRE Math Type Questions:

Question 1: Which of the following is a solution to $x(1+x)=1$ ? (a) 4 (b) -1 (c) 0 (d) $1 / 2$ (e) 1 (f) none of the above

Question 2: In a certain shop, notebooks that normally sell for 59 cents each are on sale at 2 for 99 cents. How much can be saved by purchasing 10 of these notebooks at the sale price? (a) 85 cents (b) 95 cents (c) 1.50 dollars (d) 2 dollars

Question 3: Which of the following is equal to $1 / 4$ of 0.01 percent? (a) 0 (b) 0.000025 (c) 0.00025 (d) 0.0025 (e) 0.025 (f) 0.25

(ii) Examples of GRE Analogy Type Questions:

Question 1: SEDATIVE is to DROWSINESS as: (a) epidemic is to contagiousness (b) vaccine is to virus (c) laxative is to drug (d) anesthetic is to numbness (e) therapy is to psychosis

Question 2: LAWYER is to COURTROOM as: (a) participant is to team (b) commuter is to train (c) gladiator is to arena (d) senator is to caucus (e) patient is to ward Question 3: CURIOSITY is to KNOW as: (a) temptation is to conquer (b) starvation is to eat (c) wanderlust is to travel (d) humor is to laugh |(e) survival is to live

(iii) Examples of General Trivia Questions

Question 1: What famous document begins: "When in the course of human events..."?

(a) The Magna Carta (b) The United States Constitution (c) The Declaration of Independence (d) The Oslo Accords

Question 2: What current branch of the U.S. military was a corps of only 50 soldiers when World War I broke out? (a) The U.S. Air Force (b) The U.S. Army (c) The U.S. Navy (d) The U.S. Marines

Question 3: What president was shot while walking to California Governor Jerry Brown' office? (a) Ronald Reagan (b) Jimmy Carter (c) John F. Kennedy (d) Gerald Ford

(iv) Examples of Entertainment Trivia Questions

Question 1: What movie has Anthony Perkins explain: "Understand, I don't hate her. I hate what she's become. I hate her illness"? (a) Carrie (b) Psycho (c) Terms of Endearment (d) Ordinary People

Question 2: Who was the first person since Orson Welles to be up for four Oscars in a single year, in 1982? (a) Jack Nicholson (b) Clint Eastwood (c) Warren Beatty (d) Martin Scorcesse

Question 3: What was the first Arnold Schwarzenegger movie to win four Academy Awards? (a) Terminator (b) Terminator 2 (c) True Lies (d) Rocky

\section{(v) Examples of GRE Type Sentence Completion Questions}

Question 1: Nonviolent demonstrations often create such tensions that a community that has constantly refused to can no longer be its injustices is forced to correct them: the injustices . Choose option that best completes sentence) (a) 
acknowledge...ignored (b) decrease...verified (c) tolerate...accepted (d) address...eliminated (e) explain...discussed

Question 2: Since 1813 reaction to Jane Austen's novels has oscillated between and condescension; but in general later writers have esteemed her works more highly than most of her literary . Choose option that best completes sentence) (a) dismissal...admirers | adoration...contemporaries (b) disapproval...readers (c) indifference...followers (d) approbation...precursors

Question 3: There are, as yet, no vegetation types or ecosystems whose study has been to the extent that they no longer ecologists. (Choose option that best completes sentence) (a) perfected...hinder (b) exhausted...interest (c) prolonged...require (d) prevented...challenge (e) delayed...benefit

\section{(vi) Examples of Sports Trivia Questions}

Question 1: What racket sport can be played with four balls of differing bouncing qualities? (a) Tennis (b) Squash (c) Basketball (d) Cricket

Question 2: What pro athlete is nicknamed "The Dream"? (a) Clyde Drexler (b) Michael Jordan (c) Hakeem Olajuwon (d) Scottie Pippen

Question 3: What Giant's bone-crushing 1985 tackle ended Joe Theismann's career? (a) Lawrence Taylor (b) Michael Strahan (c) Reggie White (d) Bruce Smith 


\section{Appendix 2 - Instructions to participants for Earnings Unknown Treatment}

\section{Instructions to Participants}

Thank you very much for your participation. Please read the following instructions closely. They describe the game you will be playing and how your final payoff for participating in the experiment will be determined. At no time will you be lied to or misled at any point in the experiment regarding how the experiment will proceed and how your final payoff will be determined.

\section{The Experiment}

This experiment will consist of a practice round and six real rounds. In each real round you will be presented a series of questions and given four minutes to answer as many as you can. For each question you answer correctly, you will earn some amount of tokens, where the number of tokens you earn for each correct answer is said to be your "rate-of-return" (ROR) and is a randomly determined number between 2 and 17, which will be revealed to you prior to your answering of questions. So, your earnings in a given round in tokens will equal the number of questions that you answer correctly times your realized ROR for that round. At the end of the experiment, each token will be worth $\$ 0.10$. This means each correct answer can earn you between $\$ 0.20$ and $\$ 1.70$ depending on your realized ROR.

After your four minutes for answering questions are up you will learn your total earnings (in tokens) for that round, as well as where your earnings fit in the overall distribution of all participants' earnings for that round.

However, the key component of this game is that prior to answering any questions or knowing your ROR in a given round, you will be asked to propose a re-distribution rule $p$, where $p$ is a number between zero and one. Your choice of $p$ works as a re-distribution rule in the following way: at the end of a round, the re-distribution rule $p$ that is proposed by one of the participants in this room will be randomly selected, revealed to all participants, and then implemented by the experiment administrator. If we denote the implemented re-distribution rule as $p^{*}$, then implementation means that a fraction $p^{*}$ of each participant's earnings for that round will be taken from each of participant and split evenly across all of the participants here today.

Thus, if there were three participants and if a participant $i$ 's earnings in a given round are denoted $E_{i}$, then for a given implemented distribution rule $p$, participant 1's final payoff from that round will be equal to $(1-p) \mathrm{E}_{1}+p\left(\mathrm{E}_{1}+\mathrm{E}_{2}+\mathrm{E}_{3}\right) / 3$. Note that this is equivalent to $(1-p) \mathrm{E}_{1}+p \mathrm{E}_{\mathrm{Avg}}$. Therefore, if the implemented $p$ is zero, each person's final payoff for that round simply equals his or her earnings from that round. Alternatively, if the implemented $p$ equals one, each person's final payoff for that round will all be identical and equal to the average earnings over all participants in that round. Obviously, if the implemented $p$ is greater than zero and less than one, each person's final payoff for that round will be between his or her own earnings from that round and the average earnings over all participants in that round. Therefore, the lower the implemented re-distribution rule $p$, the closer each participant's final payoff for that round will be to his or her earnings from that round, while the higher the implemented $p$, the more equal each participants' final payoff will be to the average earnings across all participants.

To help illustrate how this game works more concretely, consider the following example. Suppose there are three participants: Annie, Bill, and Charlie. In a given round, Annie drew a rate-of-return of 8 and answered 5 questions correctly, meaning her earnings for that round were 40 tokens. Similarly, suppose Bill drew a rate-of-return of 4 and answered 8 questions correctly. This would mean his earnings that round were 32 tokens. Finally, suppose Charlie drew a rate-of- 
return of 2 and answered 10 questions correctly, meaning his earnings for that round were 20 tokens.

Now, suppose Annie proposed a re-distribution rule $p$ equal to 0 , Bill proposed a $p$ equal to 0.25 , and Charlie proposed a $p$ equal to 0.75 . Given these choices and the above earnings, if Annie's proposed $p$ (equal to 0 ) turns out to be the randomly selected re-distribution rule that is implemented, no tokens will be re-distributed. Therefore, in this scenario, each person's final payoff from that round will simply equal his or her earnings from that round, meaning Annie will have a payoff of 40 tokens that round, Bill will have a payoff of 32 tokens that round, and Charlie will have a payoff of 20 tokens that round.

Alternatively, if Bill's proposed $p$ (equal to 0.25 ) is randomly selected to be the redistribution rule that is implemented, then $25 \%$ of each person's earnings are re-distributed equally to everyone, so Annie's payoff for that round will equal $(1-0.25) * 40+0.25 *(32+40+20) / 3=37.67$ tokens, Bill's payoff for that round will equal $(1-0.25) * 32+0.25 *(32+40+20) / 3=31.67$ tokens, and Charlie's payoff for that round will equal $(1-0.25) * 20+0.25 *(32+40+20) / 3=22.67$ tokens.

Finally, if Charlie's proposed $p$ equal to 0.75 is randomly selected to be the redistribution rule that is implemented, then $75 \%$ of each person's earnings are re-distributed to everyone, so Annie's payoff for that round will equal $(1-0.75) * 40+0.75 *(32+40+20) / 3=33$ tokens, Bill's payoff for that round will equal $(1-0.75) * 32+0.75 *(32+40+20) / 3=31$ tokens, and Charlie's payoff for that round will equal $(1-0.75) * 20+0.75 *(32+40+20) / 3=28$ tokens.

This example is summarized in the table below. Please take a minute to look it over.

\begin{tabular}{|c|c|c|c|c|c|c|c|}
\hline \multirow[b]{3}{*}{ Annie } & \multirow[b]{2}{*}{ rate-of-return } & \multirow[b]{2}{*}{ correct answers } & \multirow[b]{2}{*}{ earnings } & \multirow[b]{2}{*}{ chosen $p$} & \multicolumn{3}{|c|}{ Final payoff in tokens for this round } \\
\hline & & & & & $\begin{array}{l}\text { if Annie's p } \\
\text { is selected }\end{array}$ & $\begin{array}{l}\text { if Bill's p } \\
\text { is selected }\end{array}$ & $\begin{array}{l}\text { if Charlie's p } \\
\text { is selected }\end{array}$ \\
\hline & 8 & 5 & 40 & 0 & 40 & 37.67 & 33 \\
\hline Bill & 4 & 8 & 32 & 0.25 & 32 & 31.67 & 31 \\
\hline Charlie & 2 & 10 & 20 & 0.75 & 20 & 22.67 & 28 \\
\hline
\end{tabular}

\section{Round Progression and Final Payoff for Participation in this Experiment}

As stated previously, this experiment will consist of one practice round and six "real" rounds. Each round will follow the procedure listed above. The only difference across rounds will be the type of questions asked. While the practice round will contain all types of questions, in the subsequent real rounds, questions will all be of a certain type for a given round but will differ across rounds. For example, questions in one round may all relate to vocabulary, while in the next round may all relate to mathematics, and the next round may all relate to movie trivia. Furthermore, rounds will all be completely independent. Your performance, your ROR, or your choice of a re-distribution rule in one round will have no relation to what happens in subsequent rounds.

At the end of all the rounds, one of the "real" rounds will be randomly selected to be the one that "counts," meaning each participant will receive his or her payoff from that round as his or her final payoff for the experiment, where each token is worth $\$ 0.10$. You will also earn a $\$ 5$ participation fee just for being here today. 


\section{Appendix 3 - Screen Shots of Experiment Interface (Earnings Known treatment)}

国

Subject: 0

Time Remaining: 00:00

You will now be asked to propose a re-distribution rule for this match. A re-distribution rule determines what fraction of each player's earnings are taken from each player and distributed equally among all the players in this room. The re-distribution rule that will actually

be implemented in this match will be chosen at random from all the re-distribution rules proposed by players in this room.

Please use the slider below to propose your preferred re-distribution rule.

\begin{tabular}{llllllllll}
\hline 0.00 & 0.10 & 0.20 & 0.30 & 0.40 & 0.50 & 0.60 & 0.70 & 0.80 & 0.90 \\
1.00
\end{tabular}

Your Preferred Re-distribution Rule

Proceed

Your History

Switch to Tabbed View

Match Total Correct Answers ROR for Correct Answers Earnings (tokens) Your Proposed Re-distribution Rule Implemented Re-distribution Rule Your Payoff for this Match (tokens) 11 33.00

Subject: 0 Time Remaining: 00:00

The re-distribution rule that will be implemented will now be selected at random from all of the re-distribution rules proposed by the people in this room.

(i) A re-distribution rule has been implemented. Please look at your your history below for the implemented rule and your payoff for this match. Please wait for next part of the game to begin.

OK

Your History

Switch to Tabbed View

Match Total Correct Answers ROR for Correct Answers Earnings (tokens) Your Proposed Re-distribution Rule Implemented Re-distribution Rule Your Payoff for this Match (tokens)

$\begin{array}{lllllll}1 & 3 & 11 & 33.00 & 0.27 & 0.27 & 28.54\end{array}$


Appendix 4 - Additional Table

Appendix Table A-1: Regression Analysis (OLS)

\begin{tabular}{|c|c|c|c|c|}
\hline & \multicolumn{4}{|c|}{ Treatment } \\
\hline & $\begin{array}{l}\text { Earnings } \\
\text { Unknown }\end{array}$ & $\begin{array}{c}\text { Earnings } \\
\text { Known - Base } \\
\end{array}$ & $\begin{array}{l}\text { Earnings } \\
\text { Known - } \\
\text { Random } \\
\end{array}$ & $\begin{array}{c}\text { Earnings } \\
\text { Known - } \\
\text { Comm } \\
\end{array}$ \\
\hline \multicolumn{5}{|c|}{ Dependent Variable: Proposed No Redistribution $(p=0)$} \\
\hline Earnings Percentile & $\begin{array}{c}0.0506 * * \\
(0.0198)\end{array}$ & $\begin{array}{c}0.219 * * * \\
(0.0180)\end{array}$ & $\begin{array}{c}0.254^{* * *} \\
(0.0161)\end{array}$ & $\begin{array}{c}0.0938 * * * \\
(0.0209)\end{array}$ \\
\hline round & $\begin{array}{c}0.00813 \\
(0.00531)\end{array}$ & $\begin{array}{l}0.00506 \\
(0.0117)\end{array}$ & $\begin{array}{l}0.00636 \\
(0.0126)\end{array}$ & $\begin{array}{l}-0.0107 \\
(0.0113)\end{array}$ \\
\hline female & $\begin{array}{l}-0.0609 \\
(0.0851)\end{array}$ & $\begin{array}{l}-0.0765 \\
(0.0643)\end{array}$ & $\begin{array}{c}0.0296 \\
(0.0547)\end{array}$ & $\begin{array}{l}-0.0739 \\
(0.0618)\end{array}$ \\
\hline politically independent & $\begin{array}{c}0.219 \\
(0.214)\end{array}$ & $\begin{array}{c}0.0369 \\
(0.0832)\end{array}$ & $\begin{array}{l}-0.0974 \\
(0.0675)\end{array}$ & $\begin{array}{l}-0.0722 \\
(0.0451)\end{array}$ \\
\hline politically conservative & $\begin{array}{c}0.183 \\
(0.113)\end{array}$ & $\begin{array}{l}-0.0442 \\
(0.0724)\end{array}$ & $\begin{array}{c}0.155^{*} \\
(0.0821)\end{array}$ & $\begin{array}{l}0.00557 \\
(0.0726)\end{array}$ \\
\hline willingness to gamble & $\begin{array}{c}-0.00134 \\
(0.00130)\end{array}$ & $\begin{array}{c}0.00108 \\
(0.000785)\end{array}$ & $\begin{array}{c}0.00226^{* *} \\
(0.00102)\end{array}$ & $\begin{array}{c}0.00298 * * * \\
(0.000857)\end{array}$ \\
\hline Constant & $\begin{array}{l}-0.0682 \\
(0.0848)\end{array}$ & $\begin{array}{c}-0.302 * * * \\
(0.0922)\end{array}$ & $\begin{array}{c}-0.509 * * * \\
(0.0733)\end{array}$ & $\begin{array}{c}-0.136 \\
(0.0915)\end{array}$ \\
\hline R-squared & 0.175 & 0.441 & 0.600 & 0.209 \\
\hline \multicolumn{5}{|c|}{ Dependent Variable: Proposed Full Redistribution $(p=1)$} \\
\hline Earnings Percentile & $\begin{array}{l}-0.00576 \\
(0.0175)\end{array}$ & $\begin{array}{c}-0.192 * * * \\
(0.0225)\end{array}$ & $\begin{array}{c}-0.217^{* * *} \\
(0.0239)\end{array}$ & $\begin{array}{c}-0.157^{* * *} \\
(0.0273)\end{array}$ \\
\hline round & $\begin{array}{l}0.0211 * * \\
(0.00914)\end{array}$ & $\begin{array}{c}0.0305^{* *} \\
(0.0140)\end{array}$ & $\begin{array}{c}0.0192 \\
(0.0143)\end{array}$ & $\begin{array}{c}0.0292 * * \\
(0.0131)\end{array}$ \\
\hline female & $\begin{array}{l}-0.0205 \\
(0.0769)\end{array}$ & $\begin{array}{l}-0.0782 \\
(0.0638)\end{array}$ & $\begin{array}{l}-0.0729 \\
(0.0606)\end{array}$ & $\begin{array}{l}-0.0567 \\
(0.0831)\end{array}$ \\
\hline politically independent & $\begin{array}{l}0.0621 \\
(0.160)\end{array}$ & $\begin{array}{c}0.159 * \\
(0.0912)\end{array}$ & $\begin{array}{c}-0.00158 \\
(0.102)\end{array}$ & $\begin{array}{c}0.211 \\
(0.140)\end{array}$ \\
\hline politically conservative & $\begin{array}{l}-0.0629 \\
(0.0611)\end{array}$ & $\begin{array}{l}-0.0511 \\
(0.0563)\end{array}$ & $\begin{array}{c}0.150^{*} \\
(0.0777)\end{array}$ & $\begin{array}{c}0.0287 \\
(0.0875)\end{array}$ \\
\hline willingness to gamble & $\begin{array}{c}0.00216 \\
(0.00150)\end{array}$ & $\begin{array}{c}0.000149 \\
(0.000740)\end{array}$ & $\begin{array}{c}0.00296 * * \\
(0.00112)\end{array}$ & $\begin{array}{l}0.000715 \\
(0.00160)\end{array}$ \\
\hline Constant & $\begin{array}{l}-0.0134 \\
(0.128)\end{array}$ & $\begin{array}{c}0.821 * * * \\
(0.121)\end{array}$ & $\begin{array}{c}0.822 * * * \\
(0.125)\end{array}$ & $\begin{array}{c}0.663^{* * *} \\
(0.138)\end{array}$ \\
\hline R-squared & 0.089 & 0.322 & 0.470 & 0.284 \\
\hline Observations & 252 & 258 & 204 & 234 \\
\hline
\end{tabular}

